\title{
Deferoxamine accelerates endothelial progenitor cell senescence and compromises angiogenesis
}

\author{
Yi-Nan Lee ${ }^{1,2}$, Hsueh-Hsiao Wang ${ }^{3}$, Cheng-Huang Su ${ }^{1,2,3}$, Hsin-I Lee ${ }^{3}$, Yen-Hung Chou ${ }^{3,4}$, Chin-Ling \\ Hsieh $^{1,2}$, Wen-Ting Liu' ${ }^{1,2}$, Kuo-Tung Shu ${ }^{1,2}$, Kai-Ting Chang ${ }^{1,2}$, Hung-I Yeh ${ }^{1,2,3}$, Yih-Jer Wu ${ }^{1,2,3,4}$ \\ ${ }^{1}$ Cardiovascular Center, Department of Internal Medicine, MacKay Memorial Hospital, Taipei 10449, Taiwan \\ ${ }^{2}$ Department of Medical Research, MacKay Memorial Hospital, Taipei 10449, Taiwan \\ ${ }^{3}$ Department of Medicine, MacKay Medical College, New Taipei 25245, Taiwan \\ ${ }^{4}$ Institute of Biomedical Sciences, MacKay Medical College, New Taipei 25245, Taiwan
}

Correspondence to: Yih-Jer Wu; email: jacobyjwu@gmail.com, https://orcid.org/0000-0002-5146-9234

Keywords: senescence, deferoxamine, angiogenesis, endothelial progenitor cell

Received: February 19, $2021 \quad$ Accepted: August 2, $2021 \quad$ Published: September 11, 2021

Copyright: ( 2021 Lee et al. This is an open access article distributed under the terms of the Creative Commons Attribution License (CC BY 3.0), which permits unrestricted use, distribution, and reproduction in any medium, provided the original author and source are credited.

\begin{abstract}
Senescence reduces the circulating number and angiogenic activity of endothelial progenitor cells (EPCs), and is associated with aging-related vascular diseases. However, it is very time-consuming to obtain aged cells ( 1 month of repeated replication) or animals ( 2 years) for senescence studies. Here, we established an accelerated senescence model by treating EPCs with deferoxamine (DFO), an FDA-approved iron chelator. Four days of low-dose ( $3 \mu \mathrm{M})$ DFO induced senescent phenotypes in EPCs, including a senescent pattern of protein expression, impaired mitochondrial bioenergetics, altered mitochondrial protein levels and compromised angiogenic activity. DFO-treated early EPCs from young and old donors ( $<35$ vs. > 70 years old) displayed similar senescent phenotypes, including elevated senescence-associated $\beta$-galactosidase activity and reduced relative telomere lengths, colony-forming units and adenosine triphosphate levels. To validate this accelerated senescence model in vivo, we intraperitoneally injected Sprague-Dawley rats with DFO for 4 weeks. Early EPCs from DFO-treated rats displayed profoundly senescent phenotypes compared to those from control rats. Additionally, in hind-limb ischemic mice, DFO pretreatment compromised EPC angiogenesis by reducing both blood perfusion and capillary density. DFO thus accelerates EPC senescence and appears to hasten model development for cellular senescence studies.
\end{abstract}

\section{INTRODUCTION}

The therapeutic potential of endothelial progenitor cells (EPCs) for ischemic diseases has attracted great interest since Asahara et al. first identified these cells in adult peripheral blood samples in 1997 [1]. The number of circulating EPCs is reduced in diabetes mellitus patients, is negatively associated with the Framingham cardiovascular risk score [2], and is positively associated with vascular function [1-3]. EPCs are needed not only for vascular repair, but also for the regulation of angiogenesis, and thus protect organs and tissues from critical ischemia in terminal atherosclerotic diseases [2, 4]. Clinically, EPCs have been widely used to treat patients with ischemic cardiovascular disease and diabetic foot ischemia [5].

Several studies have suggested that the EPC number decreases with age in humans and animals [6-8], possibly due to EPC senescence. Aging is an independent risk factor for the development of atherosclerosis-related diseases, so EPC senescence may accordingly promote atherosclerosis in elderly patients. As progenitor cells are more senescence-resistant than proper somatic cells, timeconsuming procedures are needed to obtain sufficient quantities of senescent EPCs for routine assays. About 
one month of repeated replication is needed to obtain senescent EPCs in vitro, and about two years are needed to obtain them from old rats or mice in vivo.

Iron participates in a wide range of biological reactions, including enzyme activation, electron transfer, redox regulation, DNA damage repair and protein stabilization; thus, iron impacts cellular growth, energy metabolism and reactive oxygen species generation. Iron is required for the assembly, stability and function of respiratory complexes I, II and III for mitochondrial respiration, and also is important for the Krebs cycle, DNA metabolism and apoptosis [9]. Loss of iron homeostasis has been associated with accumulating oxidative damage and aging $[10,11]$, and increased reactive oxygen species levels due to iron deficiency can induce anemia, osteoporosis and cardiac disease [10-12].

Here, we pharmaceutically altered iron homeostasis using the Food and Drug Administration (FDA)approved iron chelator DFO, in order to establish an accelerated EPC senescence model. We treated EPCs for a short period (four days) with a low dose $(3 \mu \mathrm{M})$ of
DFO, and determined its effects on EPC cell cycle arrest, mitochondrial bioenergetics, senescence-related protein expression, lipofuscin levels [13] and senescence-associated $\quad \beta$-galactosidase $\quad(\mathrm{SA}-\beta \mathrm{Gal})$ activity. Then, we phenotypically compared these cells with EPCs that were isolated from old donors or repeatedly replicated. Our accelerated EPC senescence model may be suitable for both biochemical analyses and senolytic compound screenings.

\section{RESULTS}

\section{Short-duration, low-dose DFO treatment is sufficient to induce EPC senescence and cell cycle arrest}

We first determined the duration and dose of DFO treatment needed to accelerate EPC senescence. Late EPCs were incubated with DFO at varying concentrations $(0,1,3,10$ or $30 \mu \mathrm{M})$ for different incubation times (two, four or six days). Cell-based, quantitative measurements of senescence markers indicated that the percentage of SA- $\beta$ Gal activity-positive cells increased in a dose- and time-dependent manner upon DFO treatment (Figure 1A),

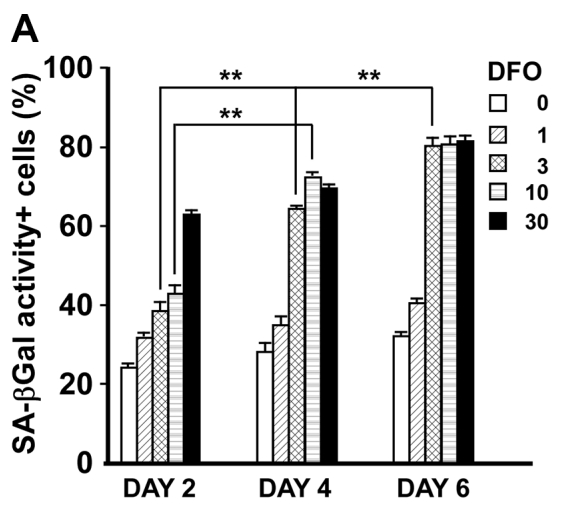

B
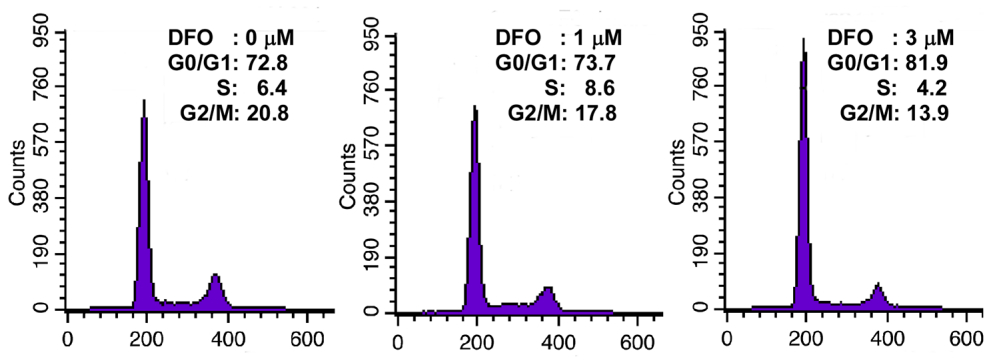

Figure 1. Short-duration, low-dose DFO treatment is sufficient to induce EPC senescence and cell cycle arrest. (A) DFO increased the percentage of SA- $\beta$ Gal activity-positive cells in a dose- and time-dependent manner. Late EPCs were treated with the indicated concentration $(\mu \mathrm{M})$ of DFO for two, four or six days. Cells were fixed, stained with X-gal and quantified. $* * P<0.01$ compared with the untreated group. $\mathrm{N}=3$. (B) DFO increased the proportion of cells remaining in the $\mathrm{GO}$ and $\mathrm{G} 1$ phases. The representative cell cycle analysis demonstrates that when different concentrations $(0,1$ and $3 \mu \mathrm{M})$ of DFO were applied to the same clone of EPCs, there were graded increases in the percentages of cells from the same passage in G0 and G1 arrest, along with reduced percentages of cells in G2 and M phase. The experiment was repeated with three different clones of EPCs with similar results. 
and that $3 \mu \mathrm{M}$ DFO treatment was sufficient to induce remarkable EPC senescence during a four-day culture process. Consistently, DFO-treated EPCs exhibited increased levels of lipofuscin, another well-accepted senescence marker [13] (Supplementary Figure 1). Likewise, at a low concentration $(3 \mu \mathrm{M})$, DFO induced remarkable G1 arrest (Figure 1B), similar to that induced via serial passaging of EPCs (P8/P13, G0-G1: 67.0\%/85.9\%; G2-M: 26.9\%/11.5\%). Therefore, a low dose $(3 \mu \mathrm{M})$ of DFO was sufficient to induce EPC senescence and cell cycle G1 arrest.

\section{DFO impairs EPC angiogenic activity}

We previously demonstrated that angiogenic activity was impaired in senescent EPCs [14]. Therefore, we examined the effects of DFO on EPC migration. DFO markedly reduced the migration of both early EPCs (Figure 2A) and late EPCs. Compared with young EPCs, old EPCs of the same clone exhibited impaired migration, and this was exacerbated by DFO treatment (Figure 2B). In addition, four-day DFO treatment dosedependently inhibited EPC tube formation (assessed
A

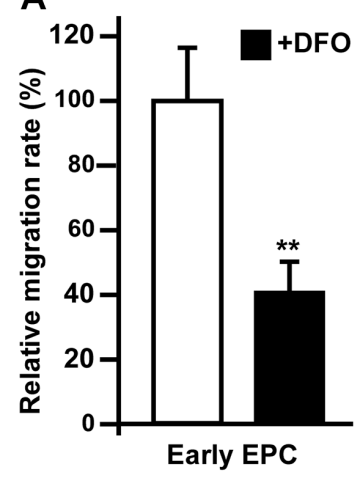

C

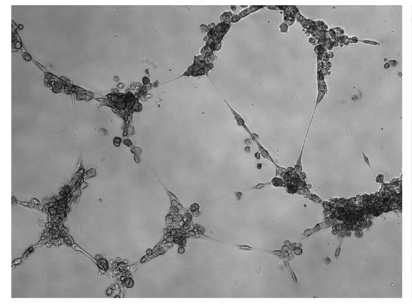

DFO

0

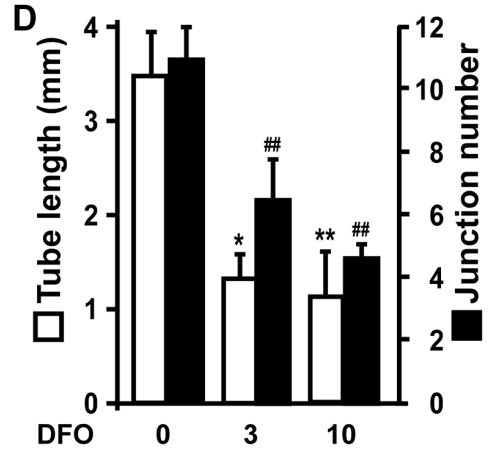

B

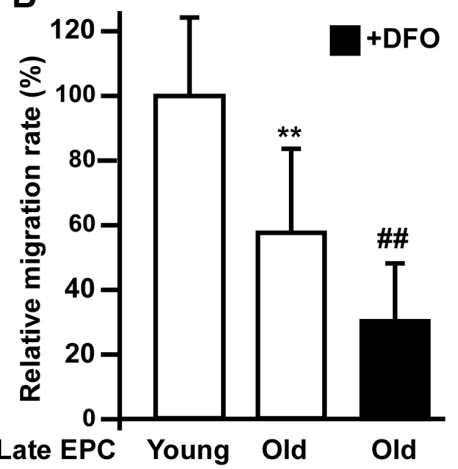

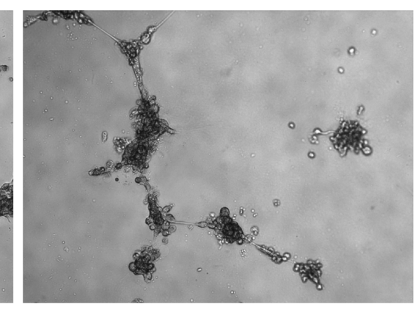

3

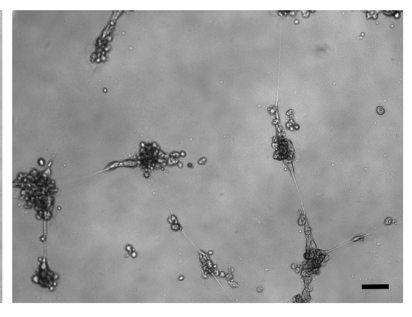

10

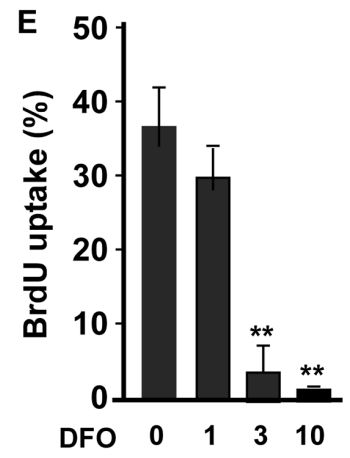

Figure 2. DFO impairs EPC angiogenic activity. (A) Early EPCs isolated from rat peripheral blood samples were treated with DFO (DFO, 3 $\mu \mathrm{M})$ for four days, and then were subjected to migration assays. ${ }^{* *} \mathrm{P}<0.01$ compared with the untreated group. (B) Migration activity was reduced in old EPCs and further attenuated by DFO treatment. Human EPCs of the same clone with 10 additional passages were defined as old EPCs, as previously described [15]. Cells were treated with or without DFO (3 $\mu \mathrm{M})$ for four days, and then were subjected to migration assays. ${ }^{* *} \mathrm{P}<0.01$ compared with the untreated group. (C) Late EPCs $\left(1 \times 10^{4}\right)$ were incubated with the indicated concentration of DFO for four days, and were harvested for tube formation assays by being seeded in matrix gel overnight. (D) Quantification of the tube length and junction number. The experiment was repeated with five different clones of EPCs with similar results. $* P<0.05, * * P<0.01$ compared with the untreated group $(0 \mu \mathrm{M})$. (E) EPCs were treated with the indicated concentration of DFO for four days, and then were subjected to a BrdU incorporation assay. ${ }^{* *} \mathrm{P}<0.01$ compared with the untreated group $(0 \mu \mathrm{M})$. 
based on tube length and junction number; Figure 2C, 2D) and proliferation (Figure 2E).

\section{DFO induces a senescent protein expression pattern in EPCs}

As DFO increased the percentage of SA- $\beta$ Gal activitypositive cells and induced senescence-like G1 arrest, we next examined whether DFO induced a senescent protein expression pattern in EPCs. Four-day DFO treatment (at 0,1 and $3 \mu \mathrm{M}$ ) dose-dependently reduced the expression of anti-senescence-related proteins such as $\mathrm{S}$ phase kinase-associated protein-2 (Skp2), cell senescence-inhibited gene (CSIG), sirtuin 1 (Sirt1) and mitochondrial fission 1 protein (Fis-1) (Figure 3A, 3B). More importantly, plasminogen activator inhibitor-1
A

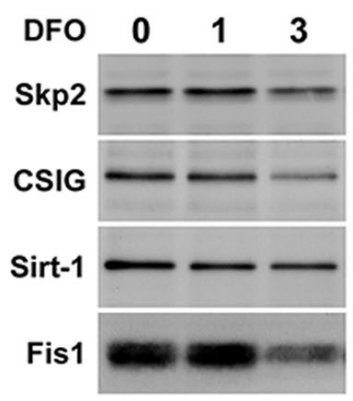

B

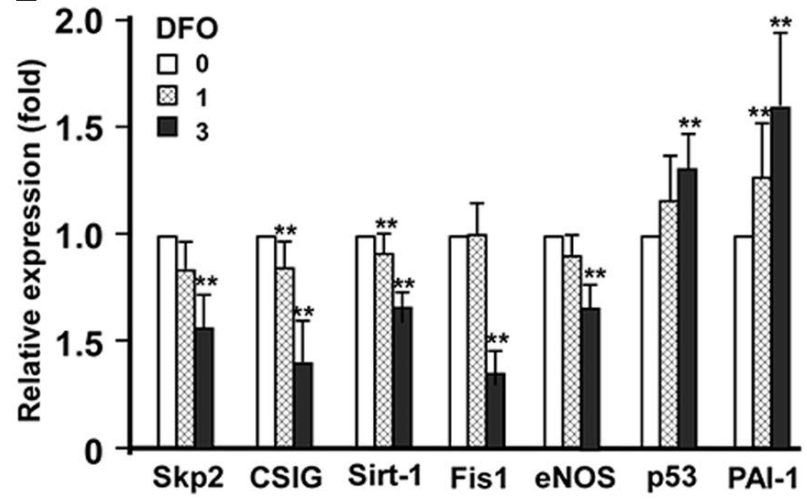

E
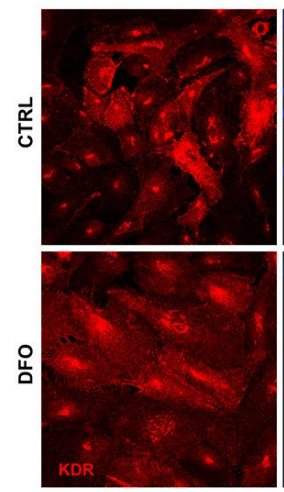
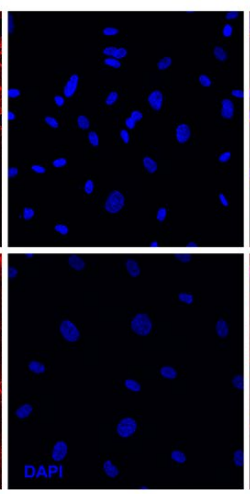<smiles></smiles>

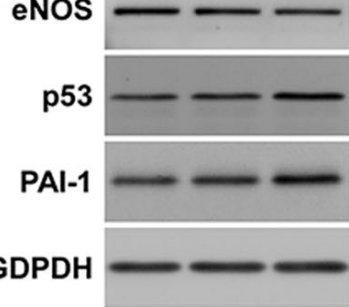

D

C
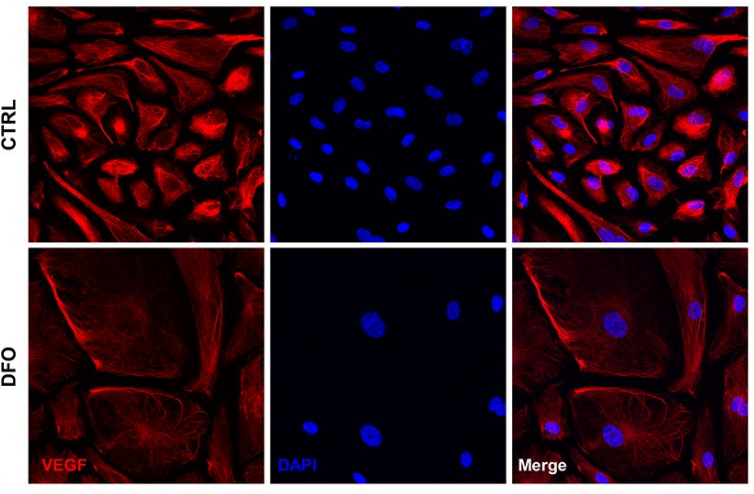

옴
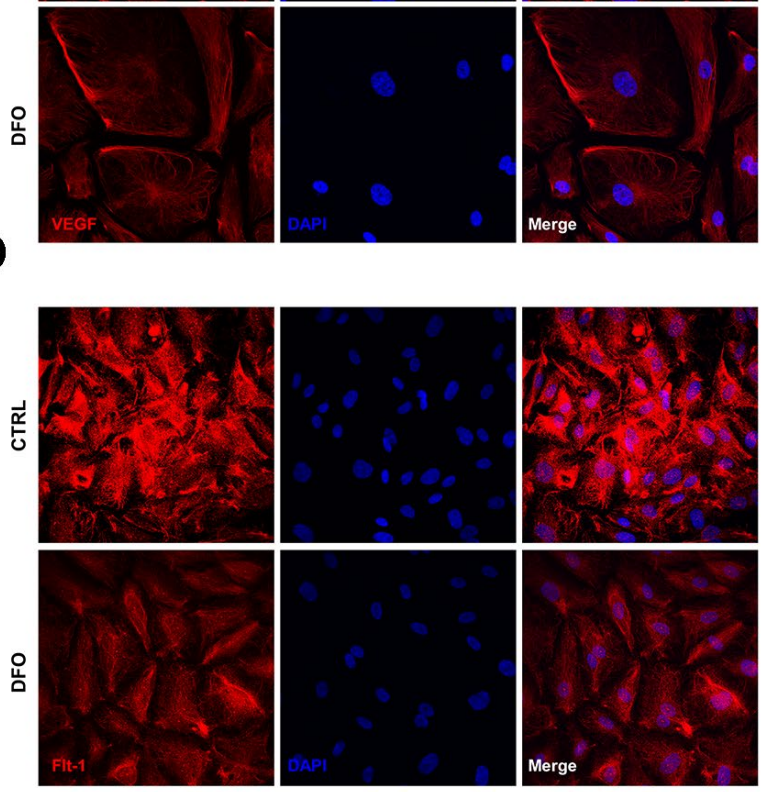

$\mathbf{F}$
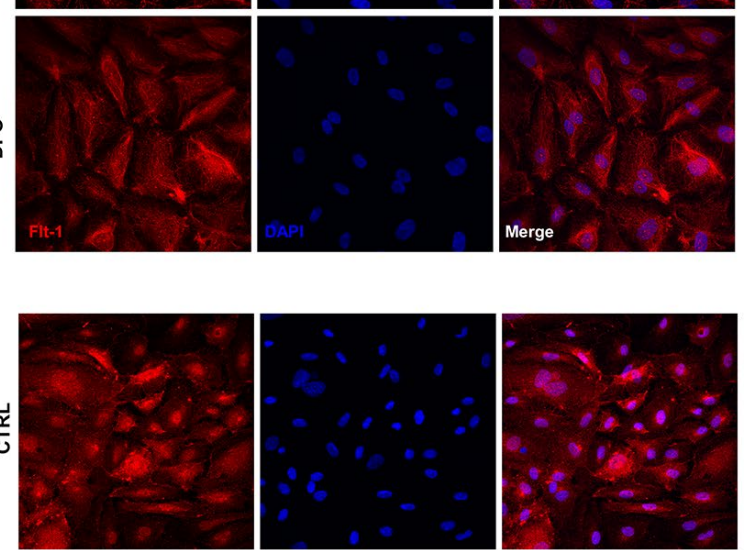
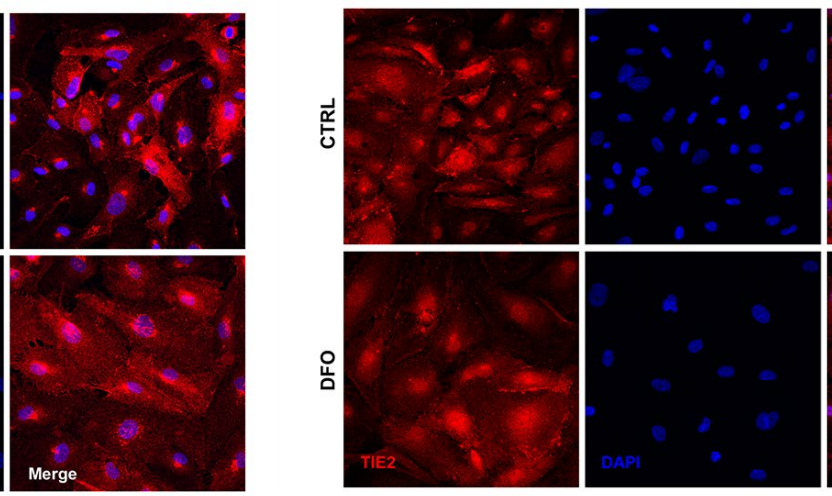

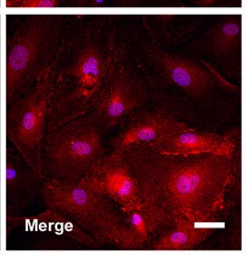

Figure 3. Effects of DFO on the expression of senescence-related proteins and angiogenic factors. (A) EPCS were treated with the indicated concentration $(\mu \mathrm{M})$ of DFO for four days. Whole-cell lysates were harvested for electrophoresis, and Western blotting was performed with the indicated antibodies. (B) Quantification of relative senescence-related protein levels, normalized to GAPDH. Values are the mean \pm standard deviation of triplicate assays from three independent experiments. ${ }^{* *} \mathrm{P}<0.01$ compared with the untreated group $(0$ $\mu M)$. (C-F) Images are cells treated without (CTRL) and with DFO on the expression of VEGF, FIt-1, KDR and TIE2, respectively. Young EPCS were treated with $3 \mu \mathrm{M}$ DFO for four days, and then were harvested for staining with the indicated antibodies. Scale bar, $50 \mu \mathrm{m}$. 
(PAI-1) and p53 were significantly upregulated, while endothelial nitric oxide synthase (eNOS) was downregulated (Figure 3A, 3B). The DFO-altered protein expression patterns in the current study are highly mimicking the phenotypes induced by repeat replication as described [14-16].

Considering that DFO compromised the angiogenic activity of EPCs, we then examined whether four-day DFO treatment altered the expression of angiogenic proteins such as vascular endothelial growth factor (VEGF), Fms-related receptor tyrosine kinase 1 (Flt-1), kinase insert domain receptor (KDR) and TEK receptor tyrosine kinase (TIE2) in EPCs (Figure 3C-3F). DFO strongly downregulated VEGF, the major angiogenic factor in EPCs, consistent with the notion that EPCs primarily promote angiogenesis through their paracrine functions [17, 18]. Flt-1, KDR and TIE2 levels were also moderately reduced in DFO-induced senescent EPCs.

\section{DFO alters EPC mitochondrial bioenergetics and dynamics}

A previous report indicated that DFO treatment progressively reduced mitochondrial complex II and IV activity [19]. Accordingly, we examined the effects of DFO on mitochondrial respiratory efficiency in EPCs. The oxygen consumption rate (OCR) curve moved markedly downward in the DFO-treated group (Figure $4 \mathrm{~A}$ ), in a pattern highly resembling that of EPCs isolated from old animals [14]. Among the quantified respiratory parameters, the mitochondrial reserve capacity and the maximal respiratory capacity of the EPCs were significantly reduced upon DFO treatment (Figure 4B), indicating that DFO reduced the respiratory efficiency. Consistent with this finding, DFO diminished the adenosine triphosphate (ATP) production rate in EPCs (Figure 4E).

We also investigated the effects of DFO on proteins involved in mitochondrial dynamics. Two mitochondrial fission proteins, Fis1 and mitochondrial protein $18 \mathrm{kDa}$ (MTP18), were significantly downregulated in old EPCs (replication-induced) compared with young EPCs, while fusion proteins such as mitofusin-1 (MFN1), MFN2 and optic atrophy 1 (OPA1) were not altered. Interestingly, chemical (DFO)- and replication-induced EPC senescence reduced Fis 1 and MTP18 expression in the same pattern (Figure 4C, 4D).

\section{DFO-treated early EPCs from young and old donors exhibit similar senescent phenotypes}

To evaluate whether ex vivo DFO treatment could mimic in vivo senescence, we harvested early EPCs from young $(<35$ year-old) and senior $(>70$ year-old) donors, and treated them with or without $3 \mu \mathrm{M}$ DFO. We then assessed the colony-forming potential of the early EPCs, which is critical for their angiogenic activity. After seven days of culture, DFO dramatically reduced the colony-forming potential of early EPCs isolated from young donors; however, its effects on senior donors' EPCs were blunted, as the colonyforming unit (CFU) counts of these cells were already low before DFO treatment (Figure 5A). However, compared to untreated groups, DFO is able to accelerate EPCs to develop other senescent phenotypes such as increased SA- $\beta$ Gal activity, reduced ATP production and diminished telomere lengths both in young and senior groups (Figure 5B-5D).

\section{DFO accelerates rat EPC senescence in vivo}

We also examined whether DFO could accelerate EPC senescence in vivo. Three-month-old Sprague-Dawley rats were administered DFO (0, 5 or $50 \mathrm{mg} / \mathrm{kg}$ /day) intraperitoneally for four weeks, and early EPCs were isolated from the rats for various assays. The results indicated that DFO pronouncedly reduced the colony formation (CFU count), increased the SA- $\beta$ Gal activity and reduced the ATP production of these cells (Figure $6 \mathrm{~A}-6 \mathrm{C})$.

$\mathrm{FeCl}_{3}$ but not antioxidant rescues the DFO-induced senescent phenotypes and proliferation inhibition

As DFO induced senescence in EPCs and various cell lines, we tested whether the antioxidants Nacetylcysteine and resveratrol could prevent DFOinduced EPC senescence, using $\mathrm{FeCl}_{3}$ as a positive control. As expected, $\mathrm{FeCl}_{3}$ almost completely reversed the induction of senescence and the inhibition of proliferation in DFO-treated EPCs (Figure 7), indicating that this senescence model is iron-sensitive. However, both antioxidants only partially rescued the DFOinduced senescent phenotypes and failed to restore cell proliferation.

The angiogenic activity of DFO-pretreated EPCs is compromised in hind-limb ischemic animals

As short-duration, low-dose DFO treatment was sufficient to induce EPC senescence, we further evaluated the angiogenic activity of DFO-treated EPCs in vivo using a hind-limb ischemia model. Mice were subjected to hind-limb ischemia 24 hours before being injected with phosphate-buffered saline (PBS), EPCs or DFO-pretreated EPCs. Then, the subcutaneous perfusion of the hind limbs was evaluated using a laser Doppler imager (Figure 8A). Blood flow was restored in the EPC-injected group, whereas blood perfusion was 

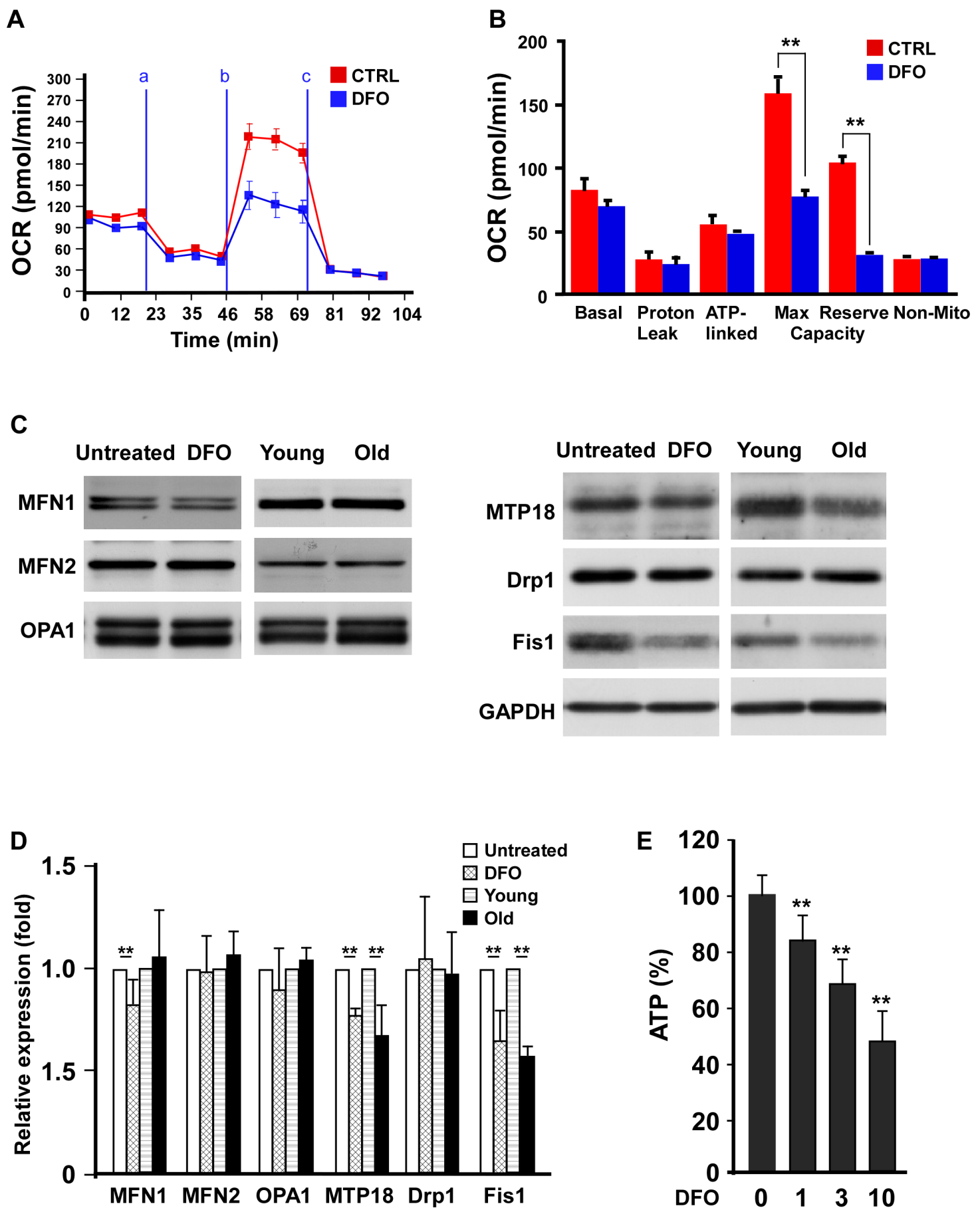

Figure 4. Deferoxamine alters EPC mitochondrial bioenergetics and dynamics. (A) DFO altered the bioenergetic profiles of human EPCs. Representative OCR curves of the EPCs are shown after the sequential addition of mitochondrial inhibitors to acquire respiratory parameters. The OCRs were automatically calculated and recorded in real time using Seahorse XF-24 software. EPCs with or without four-day $3 \mu \mathrm{M}$ DFO treatment were seeded in a non- $\mathrm{CO}_{2}$ incubator for one hour before the OCR assay. Respiratory inhibitors were injected at the indicated times ( $a$, oligomycin; $b, C C C P ; c$, antimycin A) to determine the proton leak respiration, maximal respiratory capacity and mitochondrial reserve capacity, respectively. (B) Quantitative comparison of the OCRs of EPCs in the control (CTRL, $0 \mu \mathrm{M})$ and DFO ( $3 \mu \mathrm{M})$ groups. Despite proton leak respiration and non-mitochondrial respiration, all the OCR parameters were significantly reduced in the DFO group. ${ }^{*} \mathrm{P}<0.05,{ }^{* *} \mathrm{P}<0.01$. (C) Western blots were mitochondrial proteins in EPCs with or without DFO treatment, and in young or old EPCs. (D) Quantification of Western blot images are from three independent experiments. Young EPCs were treated with DFO (3 $\mu$ M) for four days. EPCs of the same clone as the young EPCs with 10 additional passages were defined as old EPCs. (E) ATP production rate in DFO-treated EPCs. $* * P<0.01$ compared with the untreated group. The experiment was repeated with three different clones of EPCs with similar results. 
apparently attenuated in the EPC+DFO group (Figure $8 \mathrm{~B})$. Ischemic limb recovery was also better in the EPC group than in the EPC+DFO group (Figure $8 \mathrm{C}$ ); in fact, the amputation rate was $10 \%$ higher in the $\mathrm{EPC}+\mathrm{DFO}$ group than in the EPC group. Consistently, the capillary density was also higher in the EPC group than in the $\mathrm{PBS}$ and EPC+DFO groups (Figure 8D, 8E). These results suggested that DFO pretreatment attenuated the angiogenic activity of EPCs in vivo in terms of perfusion, tissue damage and capillary density.

\section{DISCUSSION}

Our study demonstrated that short-term (four days in vitro or four weeks in vivo), low-dose $(3 \mu \mathrm{M}) \mathrm{DFO}$ treatment successfully induced EPC senescence in vitro, ex vivo and in vivo, closely mimicking the senescent phenotypes induced by repeated replication or natural aging [14]. These senescent phenotypes included G1 arrest, reduced proliferation and migration, impaired neoangiogenic (tube and colony formation) potential, enhanced senescent protein or biomarker expression, and inefficient mitochondrial dynamics and bioenergetics $[14,20]$. To our knowledge, this is the first study to profile the effects of DFO on early and late EPCs. This accelerated EPC senescence model may substantially shorten the time required for many EPC senescence-related studies, particularly for the rapid screening of potential EPC senolytic agents.

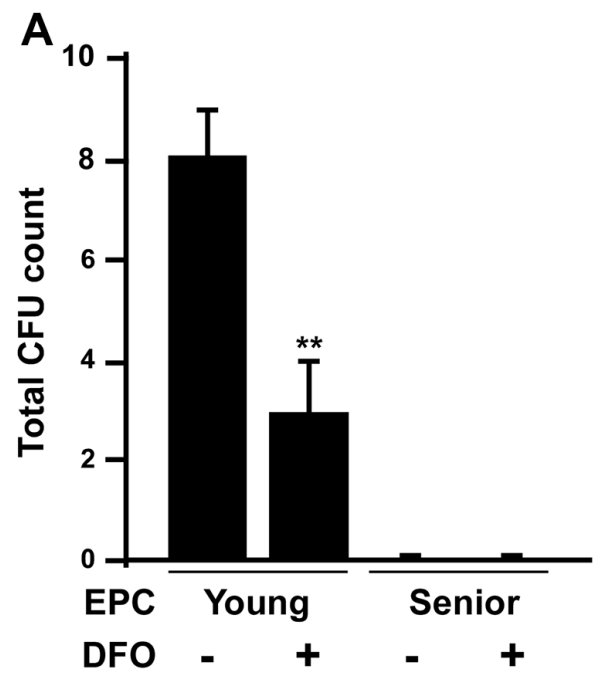

B
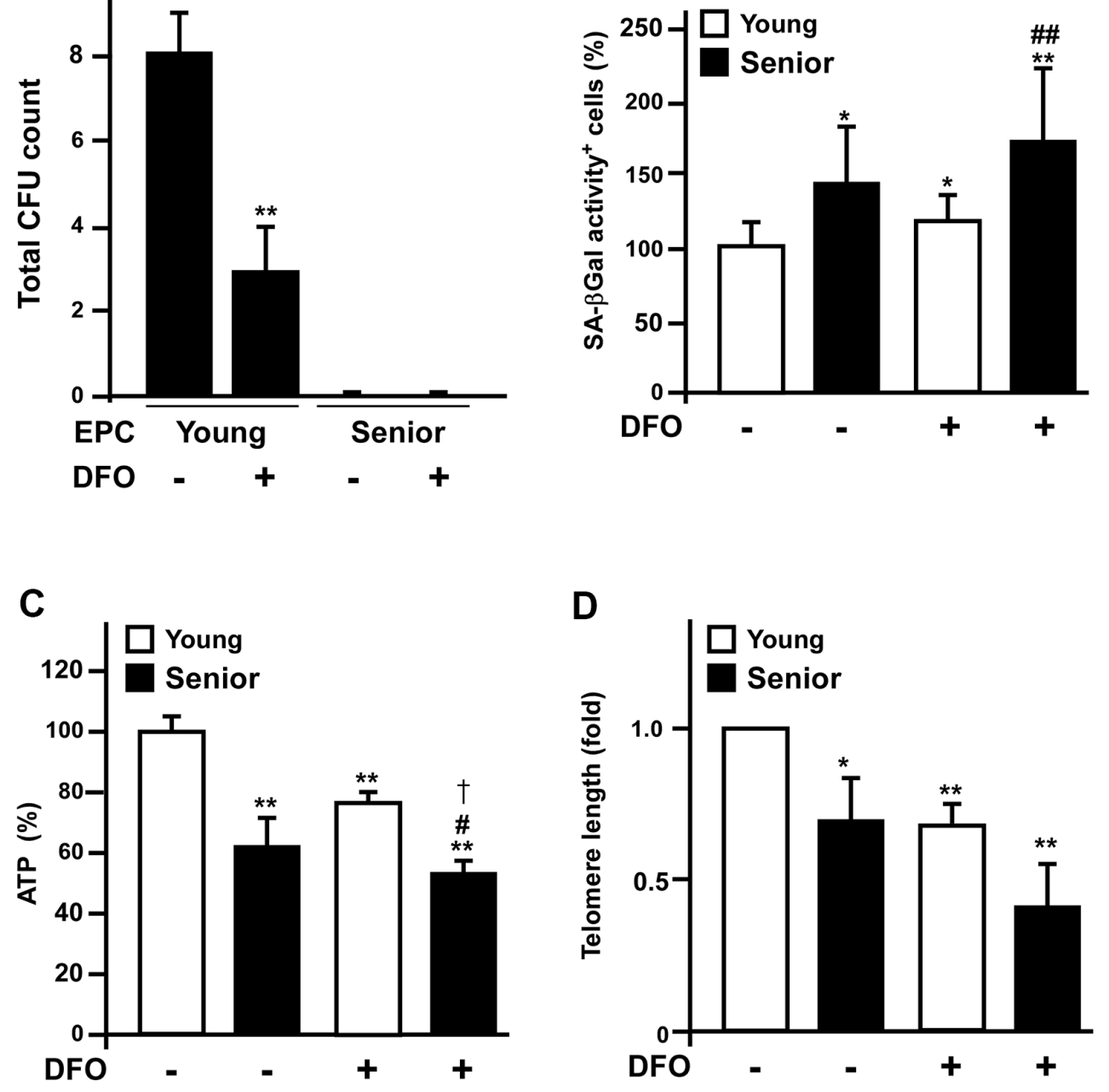

Figure 5. Deferoxamine-treated early EPCs from young donors mimic the senescent phenotypes of those from old donors. (A) Early EPCs were isolated from young (<35 year-old) and senior ( $>70$ year-old) donors for colony formation assays. Early EPCs were incubated with or without deferoxamine DFO $(3 \mu \mathrm{M})$ in a seven-day culture process. (B-D) Young and old EPCs of the same clone were treated with DFO $(3 \mu \mathrm{M})$ for four days and then assessed for SA- $\beta$ Gal activity, ATP production and telomere length. ${ }^{*} \mathrm{P}<0.05, * * \mathrm{P}<0.01$ compared with the untreated young group; \# $\mathrm{P}<0.05$, \#\# $\mathrm{P}<0.01$ compared with the untreated old group. 
A

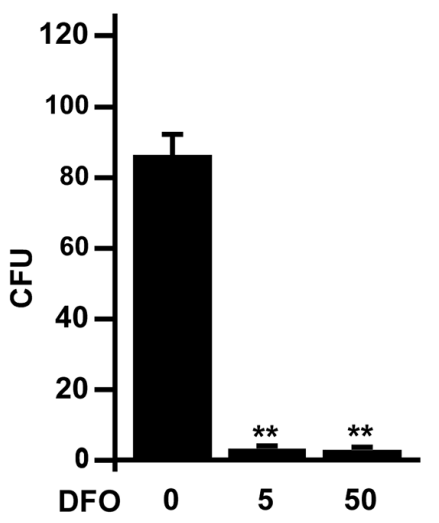

B

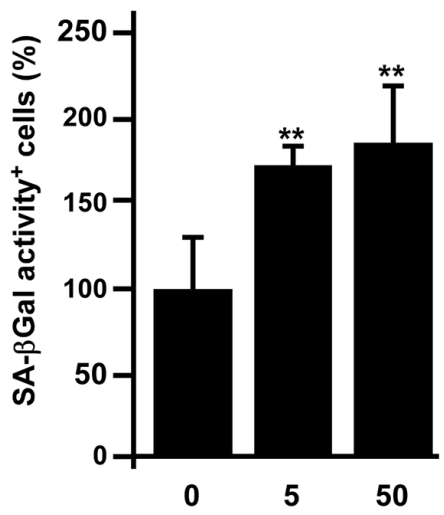

C

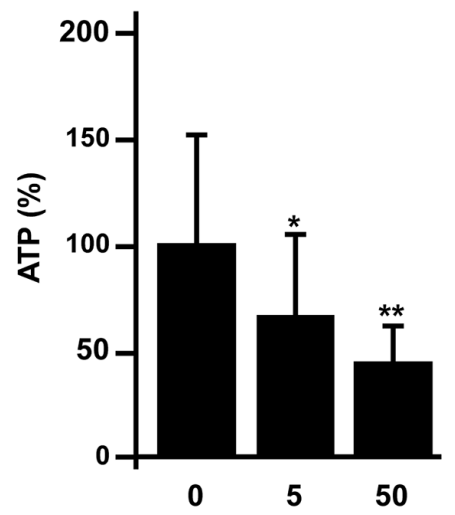

Figure 6. DFO accelerates rat early EPC senescence in vivo. (A-C) Three-month-old Sprague-Dawley rats were intraperitoneally injected with the indicated dose $(\mathrm{mg} / \mathrm{kg} / \mathrm{day})$ of DFO for four weeks. Early EPCs were harvested for assessments of colony formation, SA- $\beta$ Gal activity and ATP production. ${ }^{*} \mathrm{P}<0.05, * * \mathrm{P}<0.01$ compared with the untreated group.
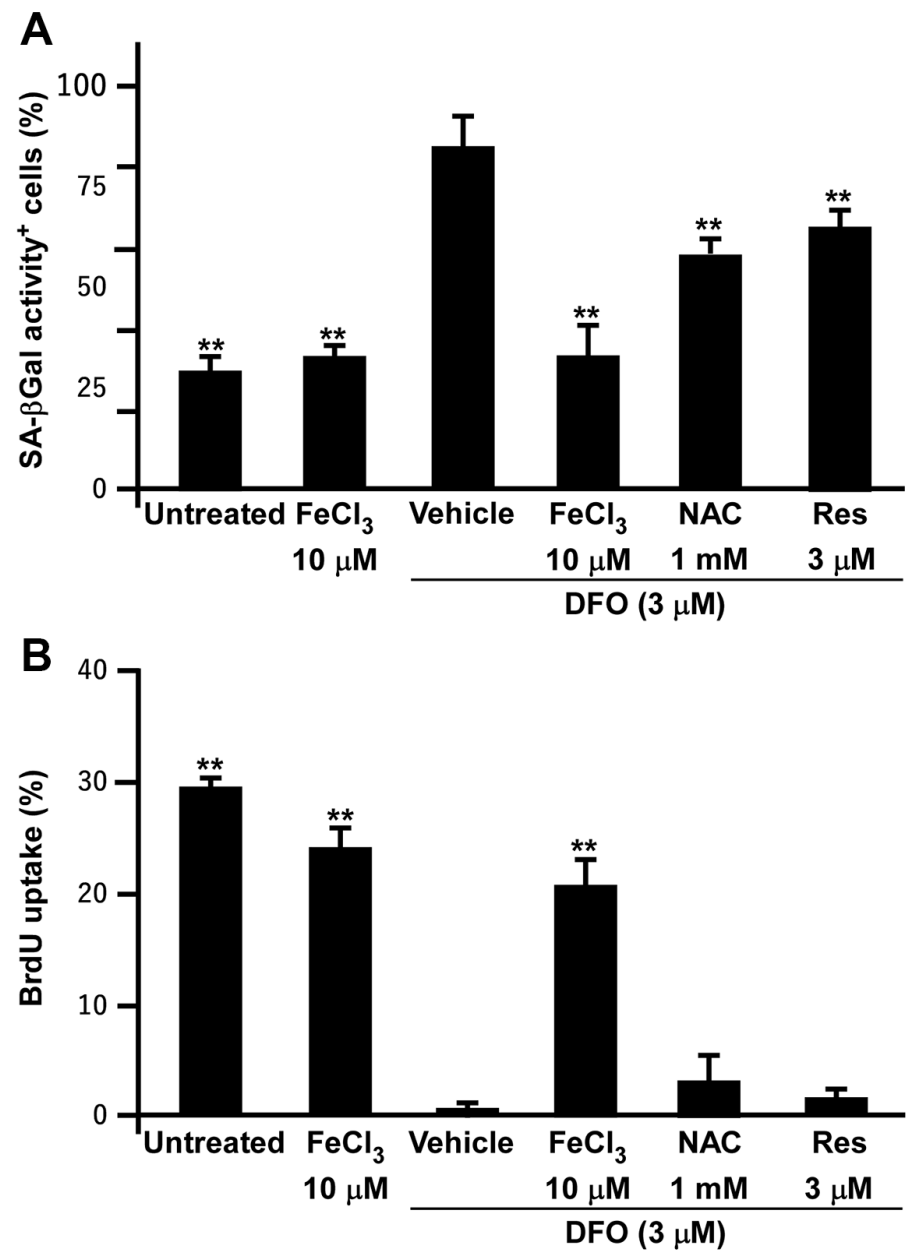

Figure 7. $\mathrm{FeCl}_{3}$ but not antioxidant rescues the DFO-induced senescent phenotypes and proliferation inhibition. (A) SA- $\beta$ Gal activity assay of EPCs. EPCs were treated with $\mathrm{FeCl}_{3}$ or DFO $(3 \mu \mathrm{M})$ plus $\mathrm{FeCl}_{3}, \mathrm{~N}$-acetylcysteine (NAC), and Resveratrol (Res) as indicated concentrations for 4 days. (B) Iron but not antioxidants rescued DFO-induced proliferation inhibition. EPCs were treated with FeCl $\mathrm{F}_{3}$ or DFO plus $\mathrm{FeCl}_{3}$ and antioxidants as described in (A). ${ }^{* *}$ Compared with vehicle, $\mathrm{P}<0.01$. 
A

Day 0

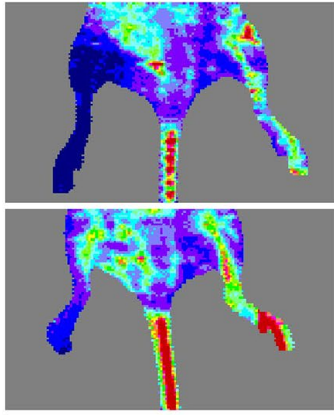

PBS

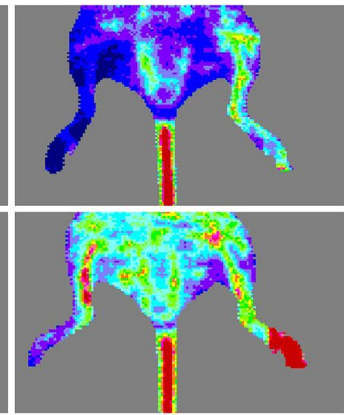

EPC

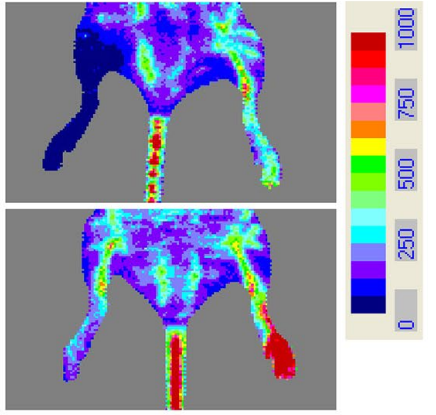

EPC+DFO

B

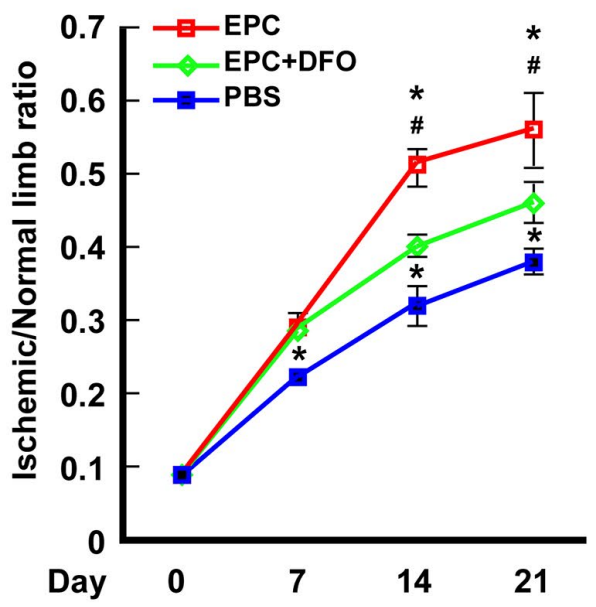

D

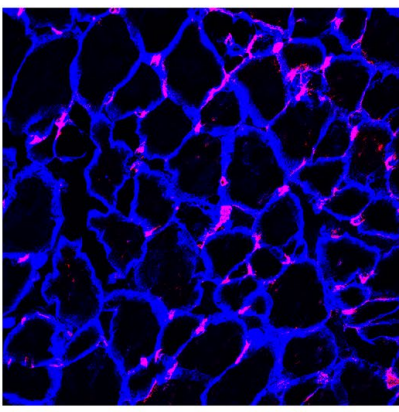

PBS

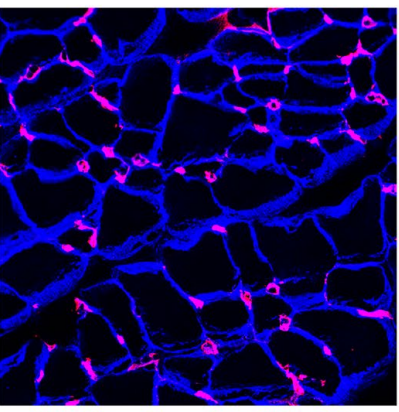

EPC
C
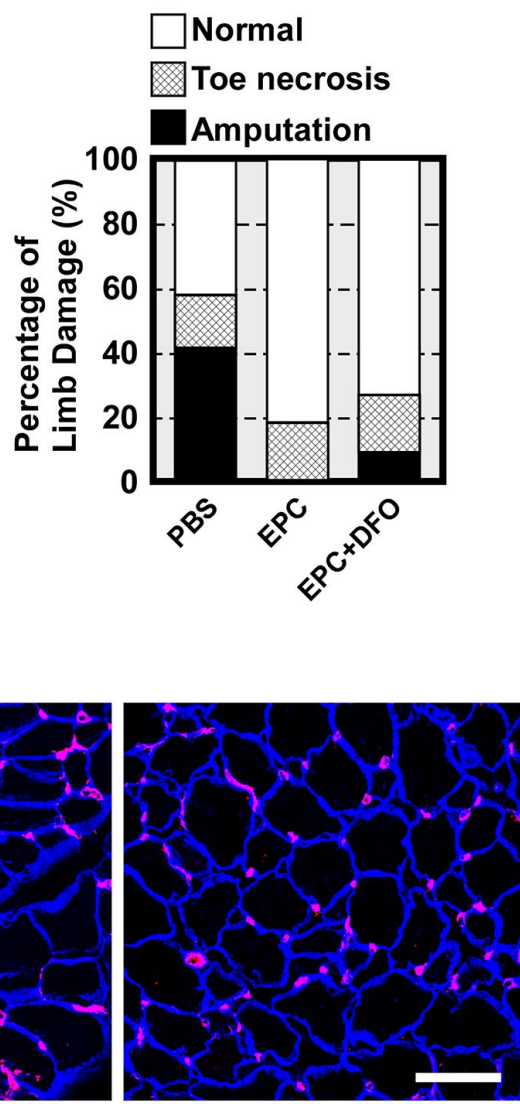

$E P C+D F O$
E

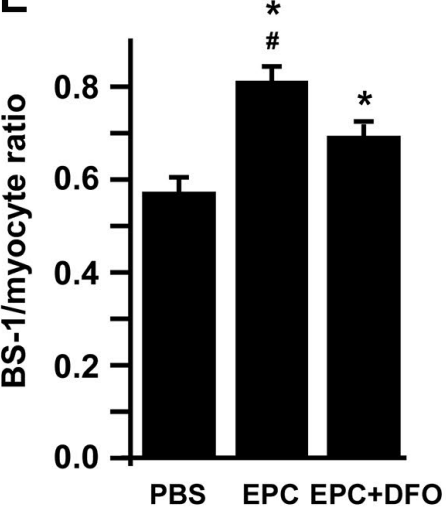

Figure 8. The angiogenic activity of DFO-pretreated EPCs is compromised in hind-limb ischemic animals. (A) Laser Doppler perfusion images of hind-limb ischemic rats injected with human EPCs to test their angiogenic activity. The rats were imaged on day 0 and day 21 after being injected with PBS, EPCs or EPCs treated with $10 \mu \mathrm{M}$ DFO for four days. PBS without EPCs served as a mock injection, while untreated right hind limbs served as the control. (B) Quantification of the ischemic area versus the normal perfusion area. The days on which the images were captured are indicated. * $\mathrm{P}<0.05$ compared with the PBS group, \# $\mathrm{P}<0.05$ compared with the DFO-treated EPC group. (C) Damaged tissues were rescued through the injection of young EPCs but not DFO-treated EPCs. The degree of tissue damage was classified into three categories: normal ( $n=10$, empty box), toe necrosis ( $n=11$, grid box) or amputation ( $n=11$, filled box). The percentage of amputated limbs was $10 \%$ higher in the DFO-treated EPC group (EPC+DFO) than in the EPC-injected group. (D) Representative images of staining for myocytes and capillaries. On day 21, tissues were sectioned and stained with laminin (blue) and Bandeiraea simplicifolia lectin 1 (BS-I, red) to visualize myocytes and capillaries, respectively. Due to tissue atrophy, the peripheries of the PBS-treated myocytes appeared to be smaller than those of the EPC-injected myocytes. (E) Quantification of capillary density, which was calculated as the number of capillaries divided by the number of myocytes. ${ }^{*} \mathrm{P}<0.05$ compared with the PBS group, \# $\mathrm{P}<0.05$ compared with the DFO-EPC group. Scale bar, $50 \mu \mathrm{m}$. 
It is well known that iron is essential for cell growth and survival, and iron overload is often observed in cancer cells. Many previous studies have demonstrated that iron deprivation can inhibit the proliferation of malignant cells; for example, in a hepatic cancer cell line, DFO was reported to promote senescence-like G1 arrest, reduce the cell growth rate and induce phenotypic biomarkers of replicative senescence (e.g., the typical flattened/enlarged morphology and enhanced SA- $\beta$ Gal activity) [21]. Here, we found that DFO induced late EPC growth arrest at G1 phase in a dosedependent manner (Figure 1B), consistent with the results of previous studies in various cell lines [22-24]. In addition to altering the cell cycle transition, DFO induced EPC senescence in a dose- and time-dependent manner, as shown in quantitative assays of SA- $\beta$ Gal activity (Figure 1). Furthermore, DFO changed the expression of senescence-related proteins in EPCs (Figure 3 and Supplementary Figure 2) to a pattern perfectly identical to that of replication-induced senescent EPCs [14]. We previously found that these anti-senescence-related proteins, Skp2, CSIG, Sirt1 and Fis-1 were downregulated. Reduced Sirt1 expression, a more senescence-specific phenomenon, was detected both in our model and in miR-34a-induced EPC senescence $[14,25]$. DFO induced senescence not only in late EPCs, but also in early EPCs obtained from rats and humans, as evidenced by increased SA- $\beta \mathrm{Gal}$ activity and reduced CFUs, telomere lengths and ATP levels (Figures 5, 6).

In addition to elevated SA- $\beta$ Gal activity, increased lipofuscin expression is another well-accepted senescence marker [13]. Consistently, DFO increased lipofuscin levels in EPCs, suggesting that DFO accelerated senescence (Supplementary Figure 1). However, DFO was previously reported to prevent lipofuscin accumulation. Marzabadi et al. found that adding $30 \mu \mathrm{M}$ ferric chloride $\left(\mathrm{FeCl}_{3}\right)$ to the culture medium of rat cardiomyocytes increased lipofuscin levels, and this effect was enhanced when the ambient oxygen concentration was raised from $20 \%$ to $40 \%$, but was counteracted when the cells were treated with high concentrations of DFO (ranging from 12.5 to $50 \mu \mathrm{M}$ ) long-term (up to 12 days) [26]. The conditions of our system differed from theirs in several ways. First, in our accelerated EPC senescence model, cells treated with low-dose DFO $(3 \mu \mathrm{M})$ for four days exhibited senescent phenotypes (Figure 1) and increased lipofuscin levels (Supplementary Figure 1). Thus, $\mathrm{FeCl}_{3}$ supplementation and high oxygen concentrations were not needed to increase lipofuscin levels in our low-dose DFO-induced EPC senescence model. Second, EPCs are stem-like, actively proliferating cells, while cardiomyocytes are post-mitotic, differentiated cells. As iron is obligate for the proliferation of cell lines and hematopoietic progenitors [27], the impacts of iron depletion on stem-like EPCs and nondividing cardiomyocytes are apparently different. Third, in breast cancer cell lines, even identical doses of DFO have been reported to have opposite effects on intracellular iron homeostasis [28, 29]. Lastly, as high concentrations of DFO can induce apoptosis [29], it may be that high-dose DFO treatment prevented lipofuscin accumulation by inducing cardiomyocyte apoptosis in the study of Marzabadi et al. Therefore, the effects of DFO on lipofuscin accumulation and intracellular iron levels may depend on the cell type (stem cell-like vs. post-mitotic) and treatment dosage.

The best-recognized hypothesis of aging was developed in the 1950s by Harman, who stated that aging is the accumulation of damage resulting from excessive oxidative stress [30]. The antioxidant effects of DFO have been reported for decades; however, these effects are unrelated to its iron-chelating properties [31, 32]. By using DFO-induced EPC senescent model to test the effects of antioxidants on cell senescent process, we find that only $\mathrm{FeCl}_{3}$ supplement rescues the DFOinduced senescent phenotypes and proliferation inhibition (Figure 7). Applying antioxidants only partially rescued the DFO-induced senescent phenotypes and failed to restore cell proliferation. Thus, the current model closely mimics the natural aging process, which is intricately regulated and cannot be reversed by free radical quenching alone. In agreement with these data, previous studies have indicated that antioxidative enzyme overexpression fails to extend the lifespans of C. elegans, fruit flies and mice [33-35].

Our model also simulated natural senescence in terms of mitochondrial dynamics and bioenergetics (Figure 4). DFO has been shown to reduce mitochondrial complex II and IV activity in other cell types [19, 36]. By monitoring the real-time OCR, we found that DFO induced a senescent pattern of mitochondrial bioenergetics in EPCs, identical to the pattern observed in EPCs isolated from old rats or subjected to replication-induced senescence [14]. Moreover, we previously demonstrated that EPC senescence could largely be attributed to the downregulation of the mitochondrial fission protein Fis1 and the accompanying changes in the mitochondrial network, whereas ectopic Fis 1 expression significantly rejuvenated replication-induced senescent EPCs [20]. In the present study, the mitochondrial dynamic protein expression pattern of DFO-treated EPCs was highly similar to that of replication-induced senescent EPCs, characterized by minor changes in fusion proteins but significant decreases in the fission proteins Fis1 and MTP18 (Figure 4C, 4D).

Several studies have demonstrated that senescence impairs the angiogenic activity of EPCs, thus increasing 
the risk of cardiovascular disease in the elderly. Indeed, we previously found that replication-induced senescent EPCs exhibited impaired tube formation, as well as diminished neoangiogenesis and perfusion recovery in hind-limb ischemic nude mice [20]. In this study, we observed that DFO dose-dependently attenuated the tube formation capacity of EPCs (Figure 2C, 2D). To determine whether DFO could also accelerate early EPC senescence, we harvested early EPCs from young ( $<35$ year-old) and old ( $>70$ year-old) donors. The EPCs from old donors nearly lost their colony-forming potential, indicating a poor ability to enhance angiogenesis [37]. Short-term in vitro DFO treatment also significantly attenuated colony formation in early EPCs from young donors (Figure 5A). Likewise, injecting Sprague-Dawley rats with DFO impaired the colony-forming potential of early EPCs in vivo (Figure 7A). DFO enhanced early EPC senescence not only by reducing the CFU count, but also by increasing SA$\beta \mathrm{Gal}$ activity, reducing ATP production and shortening the telomere length both in vitro and in vivo (Figures 5B-5D, 6B, 6C). Interestingly, several studies have shown that locally injected DFO is more of an angiogenic agent than an anti-angiogenic agent [38-40], likely because it is a hypoxia-mimetic agent that activates hypoxia inducible factor 1 alpha-dependent pathways to induce neovascularization [41, 42]. Therefore, local DFO injection may promote neovascularization by indirectly recruiting mature endothelial cells in situ, even though DFO actually reduces the angiogenic potential of circulating EPCs per se. Our present results indicated that DFO pretreatment indeed attenuated the angiogenic activity of EPCs in a hind-limb ischemic model (Figure 7).

To the best of our knowledge, this study is the first to establish an accelerated EPC senescence model using DFO. DFO-treated EPCs displayed canonical senescent phenotypes, including increased SA- $\beta$ Gal marker levels, altered senescence-related protein levels and impaired angiogenic activity. Our results indicate that establishing accelerated EPC senescence models in vitro and in vivo may expedite the very time-consuming study of EPC senescence.

\section{MATERIALS AND METHODS}

\section{Human late EPC isolation and characterization}

This study was approved by the Mackay Memorial Hospital Institutional Review Board (ethical approval no. MMHIS566). All participants provided written informed consent, and all methods were performed in accordance with the ethically approved protocol. Human late EPCs were isolated according to a previously described method [14]. In brief, peripheral blood mononuclear cells were isolated from peripheral blood samples $(80 \mathrm{~mL})$ from healthy donors through centrifugation on Ficoll-Paque ${ }^{\mathrm{TM}}$ Plus (GE Healthcare, USA) in accordance with the manufacturer's instructions. CD $34^{+}$cells were further isolated from the peripheral blood mononuclear cells using a CD34 MicroBead kit and MACSTM Cell Separation System (both from Miltenyi Biotec, Germany), and were maintained using an endothelial cell growth medium MV2 kit (PromoCell, Germany). Cells $\left(1 \times 10^{6}\right.$ cells $/ \mathrm{cm}^{2}$ ) were seeded on fibronectin-coated dishes (BD Biosciences, USA) supplemented with endothelial cell MV2 medium, and were incubated in a $5 \% \mathrm{CO}_{2}$ incubator at $37^{\circ} \mathrm{C}$.

The purified EPCs were characterized using qualified antibodies, as shown in Supplementary Figure 3. EPCs were further characterized based on their uptake of 1,1'dioctadecyl-3,3,3',3'-tetramethyl-indocarbocyanine perchlorate acetylated-low density lipoprotein (DiIacLDL), their binding to Ulex europaeus agglutinin-1 (UEA-1) lectin, and their expression of KDR, eNOS and VEGF. Old EPCs were obtained through the repeated replication of young EPCs ( passages 7-8) until their cell doubling times were twice as long as those of young EPCs from the same clone.

\section{Early EPC isolation and colony formation assay}

Early EPCs were isolated as previously described [43], with some modifications. In brief, $80-\mathrm{mL}$ peripheral blood samples were collected from healthy donors for the isolation of peripheral blood mononuclear cells. For rat EPCs, peripheral blood was obtained from the heart immediately before sacrifice. Ficoll-Paque ${ }^{\mathrm{TM}}$ Plus gradients were used during centrifugation to separate the fraction of mononuclear cells from other blood components, in accordance with the manufacturer's instructions. Mononuclear cells in the low-density fraction were harvested and washed twice with PBSethylenediaminetetraacetic acid $(2 \mathrm{mM})$. Purified mononuclear cells $\left(1 \times 10^{6} \mathrm{cells} / \mathrm{cm}^{2}\right)$ were grown on fibronectin-coated dishes (BD Biosciences) supplemented with the EGM-2 Bullet Kit system (Lonza, Switzerland), which consists of endothelial basal medium, $2 \%$ fetal bovine serum, human epidermal growth factor, human fibroblast growth factor-B, insulin-like growth factor-1, ascorbic acid and heparin. The cells were incubated in a $5 \% \mathrm{CO}_{2}$ incubator at $37^{\circ} \mathrm{C}$. The medium was changed every three days, and each cluster or colony was visually inspected daily through an inverted microscope at $40 \mathrm{X}$ magnification.

\section{Animal experiments}

All animal experiments and protocols were approved by the Institutional Animal Care and Use Committee 
of Mackay Memorial Hospital (approval numbers: MMH-A-S-970-13 and A1000003). Experiments were performed on 8- to 10-week-old male SpragueDawley rats (National Laboratory Animal Center, Taiwan) maintained under a 12-hour light/dark cycle. Standard laboratory chow and water were available ad libitum.

\section{SA- $\beta$ Gal activity measurement}

SA- $\beta$ Gal activity was quantified using a senescence assay kit (Abcam, UK) in accordance with the manufacturer's instructions. EPCs $\left(5 \times 10^{3}\right.$ cells/well $)$ were seeded on a 24-well plate in complete cell culture medium with or without $200 \mathrm{nM}$ daunorubicin $\mathrm{HCl}$ at $37^{\circ} \mathrm{C}$ with $5 \% \mathrm{CO}_{2}$. After 48 hours of incubation, the medium was replaced with senescence dye containing buffer, and the cells were incubated for two hours. The cells were then washed twice, trypsinized and analyzed using fluorescence-activated cell sorting.

Senescent cells were imaged using a $\beta$-galactosidase staining kit (BioVision, USA) according to the manufacturer's instructions. EPCs $\left(1 \times 10^{4}\right)$ in 24-well plates were washed with PBS and fixed with $0.5 \mathrm{~mL}$ of fixative solution for $15 \mathrm{~min}$ at room temperature. After being washed, the cells were incubated overnight with $\mathrm{X}$ gal $(1 \mathrm{mg} / \mathrm{mL})$ at $37^{\circ} \mathrm{C}$. The cells were then washed again and observed under a microscope at 200X magnification so that blue-colored positive cells could be counted.

\section{Measurement of cellular ATP production}

Intracellular ATP concentrations were measured using an ATP Bioluminescence Assay kit CLS II (Roche, \# 11 699695 001) in accordance with the manufacturer's instructions. Total cell lysates from $1 \times 104$ EPCs were resuspended in $100 \mu \mathrm{L}$ of dilution buffer. An ATP standard curve in the range of $10-5$ to $10-10 \mathrm{M}$ was prepared using serial dilutions of an ATP standard solution in redistilled water. The total cell lysates were diluted in nine volumes of a boiling $100 \mathrm{mM}$ Tris, 4 $\mathrm{mM}$ ethylenediaminetetraacetic acid solution ( $\mathrm{pH} 7.75)$. The samples were incubated for $2 \mathrm{~min}$ at $100^{\circ} \mathrm{C}$ and then centrifuged at $1000 \times \mathrm{g}$ for $60 \mathrm{sec}$. The supernatants were transferred to fresh tubes, and luciferase reagent was added to the samples and standards. ATP-catalyzed bioluminescence was then measured on a luminometer and integrated for 1 to 10 sec. Intracellular ATP concentrations were calculated from a log-log plot of the standard curve data.

\section{Cell growth and proliferation assay}

Cell proliferation was evaluated based on nuclear bromodeoxyuridine (BrdU) incorporation using a BrdU immunochemistry kit (Millipore, USA). EPCs $(1.5 \times$ $10^{4}$ cells/well) were grown on coverslips in a 24-well plate overnight. Six hours before the assay, the cells were incubated with $10 \mu \mathrm{M}$ BrdU. The cells were then washed twice and fixed with ice-cold $70 \%$ ethanol at $4^{\circ} \mathrm{C}$ for $30 \mathrm{~min}$. The cells were washed with PBS, blocked with $10 \%$ fetal bovine serum and incubated for two hours with an anti-BrdU antibody. After being washed three times, the cells were incubated with horseradish peroxidase-conjugated antibodies. Finally, the cells were visualized using 3,3'-diaminobenzidine tetrahydrochloride staining according to the manufacturer's instructions.

\section{Cell cycle analysis}

EPCs $\left(1 \times 10^{6}\right)$ were harvested and resuspended in single-cell suspension buffer (PBS $+2 \%$ fetal bovine serum). After being washed, the cells were fixed with ice-cold $70 \%$ ethanol and then incubated with a propidium iodide solution $(50 \mu \mathrm{g} / \mathrm{mL}$ propidium iodide, $0.1 \mathrm{mg} / \mathrm{mL}$ RNase A, $0.05 \%$ Triton X-100) at $37^{\circ} \mathrm{C}$ for $40 \mathrm{~min}$. The cells were pelleted, resuspended in $500 \mu \mathrm{L}$ of PBS and analyzed using flow cytometry on a FACScan flow cytometer (BD Biosciences).

\section{Mitochondrial functional evaluation based on the OCR}

The cellular OCR (pmol/min) was evaluated as a measure of mitochondrial function on a Seahorse Bioscience XF24 extracellular flux analyzer (Bucher Biotec AG, Switzerland). On the day of metabolic flux analysis, cells were incubated at $37^{\circ} \mathrm{C}$ in a non- $\mathrm{CO}_{2}$ incubator for one hour with customer-formulation Endothelial Cell BM MV2 medium (c-97139, PromoCell). First, the baseline cellular OCR was measured. For mitochondrial respiration analysis, ATP synthase was inhibited using the mitochondrial inhibitor oligomycin $(10 \mu \mathrm{M}$, Sigma, USA). For the analysis of the mitochondrial membrane potential and electron transport chain, the protonophore carbonyl cyanide $\mathrm{m}$ chlorophenyl hydrazine (CCCP, $50 \mu \mathrm{M}$, Sigma) and antimycin A ( $5 \mu \mathrm{M}$, Sigma) were injected as inhibitors. The relative contributions of the basal, nonmitochondrial, ATP-linked, proton leak-linked and maximal OCRs were calculated, along with the cell reserve capacity, and progress curves were plotted.

\section{Relative telomere length determination}

EPCs $\left(1 \times 10^{5}\right)$ were harvested for genomic DNA extraction to determine telomere length. PCR was conducted with a mixture of $270 \mathrm{nM}$ telomere sense primers, $900 \mathrm{nM}$ telomere antisense primers and $1 \times$ SYBR Green Master Mix (Roche, USA). The primer 
sequences used for telomere length determination were: telomere sense strand, GGTTTTTGAGGGTGAGGG TGAGGGTGAGGGTGAGGGT; telomere antisense strand, TCCCGACTATCCCTATCCCTATCCCTAT CCCTATCCCTA. The internal control sequences were: 36B4 antisense strand, CCCATTCTATCATCAAC GGGTACAA; 36B4 sense strand, CAGCAA GTGGGAAGGTGTAATCC. The reaction proceeded for one cycle at $95^{\circ} \mathrm{C}$ for $5 \mathrm{~min}$, followed by 25 cycles of $95^{\circ} \mathrm{C}$ for $15 \mathrm{sec}, 54^{\circ} \mathrm{C}$ for $2 \mathrm{~min}$, and a final extension at $72^{\circ} \mathrm{C}$ for $5 \mathrm{~min}$. Quantitative PCR was performed on an ABI One Step Real-Time PCR machine (Applied Biosystems, USA). We calculated the relative telomere length (normalized $\mathrm{T} / \mathrm{S}$ ratio) using the comparative $\mathrm{Ct}$ method after verifying that the quantitative PCR results for telomeres and 36B4 had equivalent amplification efficiencies.

\section{Western blotting analysis}

Radioimmunoprecipitation assay buffer was used to harvest total cell lysates from EPCs. The cell lysates (50 $\mu \mathrm{g} / \mathrm{sample}$ ) were resolved using sodium dodecyl sulfate polyacrylamide gel electrophoresis, and then were transferred onto polyvinylidene fluoride membranes (Bio-Rad, USA) at $4^{\circ} \mathrm{C}$ overnight. The blots were blocked with $10 \%$ bovine serum albumin and then incubated with primary antibodies (diluted 1:1000) for two hours at room temperature to detect proteins associated with senescence, the cell cycle, mitochondrial function or endothelial cell function. The antibodies included Sirt1 (Sigma), CSIG (GeneTex, USA), Skp2 (Cell Signaling Technology, MA, USA), p53 (Epitomics, USA), MFN1 (Santa Cruz Biotechnology, USA), MFN2 (Cell Signaling Technology), OPA1 (Cell Signaling Technology), MTP18 (Abcam), Drp1 (Santa Cruz), Fis1 (Sigma), eNOS (BD Biosciences) and PAI-1 (Abcam). Corresponding secondary antibodies conjugated with alkaline phosphatase were used, and the chemiluminescence reaction was conducted using VisiGlo substrate (Amresco, USA) in accordance with the manufacturer's instructions. The blots were scanned and densitometric analyses were performed using TotalLab software (Nonlinear Dynamics).

\section{Hind-limb ischemia in nude mice and EPC angiogenesis}

To create ischemic hind limbs, we anesthetized female $\mathrm{BALB} / \mathrm{c}$ athymic nude mice (8 weeks old, weighing 18$22 \mathrm{~g})$ by intraperitoneally injecting them with pentobarbital $(80 \mathrm{mg} / \mathrm{kg})$. The right femoral artery and vein were ligated and severed from just above the deep femoral arteries to the popliteal artery and vein. Twenty-four hours after surgery, the right thighs and calves of the mice were injected with one of the following reagents: 1) $50 \mu \mathrm{L}$ of PBS alone (PBS group), 2) PBS containing young EPCs $\left(2 \times 10^{5}\right.$, EPC group), or 3) PBS containing young EPCs $\left(2 \times 10^{5}\right)$ pretreated with $10 \mu \mathrm{M}$ DFO for four days (EPC+DFO group). After 21 days, the mice were sacrificed with an overdose of intraperitoneal pentobarbital $(100 \mathrm{mg} / \mathrm{kg})$, and their calf muscles were dissected and processed for immunohistochemical analysis.

\section{Laser doppler perfusion imaging}

The subcutaneous perfusion of the hind limbs was evaluated using a laser Doppler imager (Moor Instruments, UK). Mice without amputated hind limbs were anesthetized with pentobarbital $(80 \mathrm{mg} / \mathrm{kg}$, intraperitoneal) and placed on a heater at $37^{\circ} \mathrm{C}$ for 10 min before their ischemic legs and feet were scanned. Laser Doppler imaging was performed 24 hours after surgery (day 0, just before the injection of EPCs). The same procedures were performed on days 7,14 and 21 after EPC injection. The subcutaneous perfusion status of the right (ischemic) hind limb was expressed relative to that of the left (normal) hind limb.

\section{Immunofluorescence}

Confluent EPCs on cover glasses were fixed with 4\% paraformaldehyde (electron-microscopy grade, Electron Microscopy Sciences, USA) for $10 \mathrm{~min}$ and then washed three times with PBS. The cells were blocked with $10 \%$ horse serum for one hour and incubated with primary antibodies (all diluted 1:100) at $4^{\circ} \mathrm{C}$ overnight. The following antibodies were used: platelet-endothelial cell adhesion molecule-1 (PECAM1, CD31; MA3105; Invitrogen), VE-cadherin (sc-9989; Santa Cruz), Flt-1 (ab2350; Abcam), TIE2 (ab24859; Abcam), eNOS (32027; Cell Signaling Technology), KDR (2479S; Cell Signaling Technology), VEGF (1909-S; Epitomics) and vWF (AHP062; Bio-Rad). After being washed three times with PBS-Triton X-100 $(0.2 \%)$, the cells were incubated with the corresponding secondary antibodies at room temperature for three hours. Cell nuclei were stained with 4',6-diamidino-2'-phenylindole (DAPI, 1 $\mathrm{mg} / \mathrm{mL}$, diluted $3000 \mathrm{X}$ ) for $10 \mathrm{~min}$ and then washed three times with PBS-Triton X-100 $(0.2 \%)$. The cells cultured on cover glasses were mounted with ProLong ${ }^{\mathrm{TM}}$ Mountant (Invitrogen, USA) and imaged with a Leica TCS SP8 confocal microscope (Germany).

Calf muscles were placed in $30 \%$ sucrose-PBS for 24 hours, bisected at the middle level, mounted in an optimal cutting temperature compound (Tissue-Tek) and snap-frozen in liquid nitrogen. For the capillary density analysis, the calf muscles were mid-bisected, with one cross-section $1.5 \mathrm{~mm}$ above the bisecting 
plane and another cross-section $1.5 \mathrm{~mm}$ below the bisecting plane, so that the two sections were $3 \mathrm{~mm}$ apart. Both sections were fixed with methanol for 10 min, washed briefly with PBS, blocked with $10 \%$ horse serum, and labeled with a mixture of a monoclonal rat anti-murine PECAM1 (CD31) antibody (1:200; B and D Pharmingen, USA) and a polyclonal rabbit antilaminin antibody (1:100; Chemicon) at $37^{\circ} \mathrm{C}$ for two hours. The sections were then incubated with a mixture of a CY3-conjugated anti-rat antibody and a CY5conjugated anti-rabbit antibody (both from Chemicon). In parallel, methanol-fixed frozen sections were stained with tetramethylrhodamine isothiocyanate-conjugated murine EC-specific Bandeiraea simplicifolia lectin 1 (BS-I, 1:50; Sigma) and a polyclonal rabbit anti-laminin antibody $(1: 100$; Chemicon $)$ at $4^{\circ} \mathrm{C}$ overnight, and then were incubated with a CY5conjugated anti-rabbit antibody. Capillaries were counted in 30 randomly chosen high-power fields on the two sections from each animal (without amputated hind limbs). The results are expressed as capillaries per myocyte.

\section{Statistical analyses}

Values are expressed as the mean \pm standard deviation. Student's $t$ test was used to assess differences between the means of two groups, while analysis of variance was used to assess differences among the means of three or more groups. A linear regression or curve-fitting test was used to assess the correlation between two variables. $\mathrm{P}$ values $<0.05$ were considered statistically significant.

\section{Abbreviations}

CFU: colony-forming unit; CSIG: cell senescenceinhibited gene; DFO: deferoxamine; Drp1: dynaminrelated protein 1; eNOS: endothelial nitric-oxide synthase; EPC: endothelial progenitor cell; Fis1: mitochondrial fission 1 protein; MFN1: mitofusin-1; MTP18: mitochondrial protein $18 \mathrm{kDa}$; OCR: oxygen consumption rate; plasminogen activator inhibitor-1: PAI-1; Sirt1: sirtuin (silent mating type information regulation 2 homolog) 1; SA- $\beta$ Gal: senescenceassociated $\beta$-galactosidase; Skp2: S phase-associated protein-2.

\section{AUTHOR CONTRIBUTIONS}

YNL helped to conceive this study and draft the manuscript. WTL and KTS collected and characterized the human EPCs. KTC and HIL performed the biochemical and molecular biology experiments. CLH and YHC participated in the animal experiments. HHW, CHS and HIY acquired, analyzed and interpreted all the data. YJW conceived the study, analyzed the results and wrote the manuscript. All authors read and approved the final manuscript.

\section{CONFLICTS OF INTEREST}

The authors declare that they have no conflicts of interest.

\section{FUNDING}

This work was supported by grants from the Ministry of Science and Technology of Taiwan (101-2314-B-715001-MY2) and Mackay Memorial Hospital (MMH-E103-03).

\section{REFERENCES}

1. Asahara $T$, Murohara $T$, Sullivan $A$, Silver $M$, van der Zee R, Li T, Witzenbichler B, Schatteman G, Isner JM. Isolation of putative progenitor endothelial cells for angiogenesis. Science. 1997; 275:964-67. https://doi.org/10.1126/science.275.5302.964 PMID: 9020076

2. Hill JM, Zalos G, Halcox JP, Schenke WH, Waclawiw MA, Quyyumi AA, Finkel T. Circulating endothelial progenitor cells, vascular function, and cardiovascular risk. N Engl J Med. 2003; 348:593-600.

https://doi.org/10.1056/NEJMoa022287

PMID: 12584367

3. Imanishi T, Hano T, Sawamura T, Nishio I. Oxidized lowdensity lipoprotein induces endothelial progenitor cell senescence, leading to cellular dysfunction. Clin Exp Pharmacol Physiol. 2004; 31:407-13.

https://doi.org/10.1111/j.1440-1681.2004.04022.x PMID:15236625

4. Vasa M, Fichtlscherer S, Aicher A, Adler K, Urbich C, Martin H, Zeiher AM, Dimmeler S. Number and migratory activity of circulating endothelial progenitor cells inversely correlate with risk factors for coronary artery disease. Circ Res. 2001; 89:E1-7.

https://doi.org/10.1161/hh1301.093953 PMID: 11440984

5. Tepper OM, Galiano RD, Capla JM, Kalka C, Gagne PJ, Jacobowitz GR, Levine JP, Gurtner GC. Human endothelial progenitor cells from type II diabetics exhibit impaired proliferation, adhesion, and incorporation into vascular structures. Circulation. 2002; 106:2781-86. https://doi.org/10.1161/01.cir.0000039526.42991.93 PMID:12451003

6. Zwerschke W, Mazurek S, Stöckl P, Hütter E, Eigenbrodt $E$, Jansen-Dürr P. Metabolic analysis of senescent human fibroblasts reveals a role for AMP in 
cellular senescence. Biochem J. 2003; 376:403-11. https://doi.org/10.1042/BJ20030816

PMID:12943534

7. Umemura T, Soga J, Hidaka T, Takemoto H, Nakamura S, Jitsuiki D, Nishioka K, Goto C, Teragawa H, Yoshizumi M, Chayama K, Higashi Y. Aging and hypertension are independent risk factors for reduced number of circulating endothelial progenitor cells. Am J Hypertens. 2008; 21:1203-09.

https://doi.org/10.1038/ajh.2008.278 PMID:18787520

8. Jie $\mathrm{KE}$, Goossens $\mathrm{MH}$, van Oostrom $\mathrm{O}$, Lilien $\mathrm{MR}$, Verhaar MC. Circulating endothelial progenitor cell levels are higher during childhood than in adult life. Atherosclerosis. 2009; 202:345-47.

https://doi.org/10.1016/i.atherosclerosis.2008.05.012 PMID:18571177

9. Stiban J, So M, Kaguni LS. Iron-Sulfur Clusters in Mitochondrial Metabolism: Multifaceted Roles of a Simple Cofactor. Biochemistry (Mosc). 2016; 81:1066-80.

https://doi.org/10.1134/S0006297916100059

PMID:27908232

10. Min KS, Sano E, Ueda H, Sakazaki F, Yamada K, Takano M, Tanaka K. Dietary Deficiency of Calcium and/or Iron, an Age-Related Risk Factor for Renal Accumulation of Cadmium in Mice. Biol Pharm Bull. 2015; 38:1557-63. https://doi.org/10.1248/bpb.b15-00341 PMID:26228629

11. Xu J, Marzetti E, Seo AY, Kim JS, Prolla TA, Leeuwenburgh $C$. The emerging role of iron dyshomeostasis in the mitochondrial decay of aging. Mech Ageing Dev. 2010; 131:487-93.

https://doi.org/10.1016/j.mad.2010.04.007 PMID:20434480

12. Uehara M, Tateishi S, Chiba H, Suzuki K, Goto S. Effects of iron and copper supplementation on the formation of thiobarbituric acid-reactive substances and phosphatidylcholine hydroperoxide in the livers of iron- and copper-deficient rats. J Nutr Sci Vitaminol (Tokyo). 1998; 44:705-14.

https://doi.org/10.3177/insv.44.705

PMID: $\underline{919490}$

13. Georgakopoulou EA, Tsimaratou K, Evangelou K, Fernandez Marcos PJ, Zoumpourlis V, Trougakos IP, Kletsas D, Bartek J, Serrano M, Gorgoulis VG. Specific lipofuscin staining as a novel biomarker to detect replicative and stress-induced senescence. A method applicable in cryo-preserved and archival tissues. Aging (Albany NY). 2013; 5:37-50.

https://doi.org/10.18632/aging.100527

PMID:23449538

14. Garcia V, Park EJ, Siragusa M, Frohlich F, Mahfuzul
Haque M, Pascale JV, Heberlein KR, Isakson BE, Stuehr DJ, Sessa WC. Unbiased proteomics identifies plasminogen activator inhibitor-1 as a negative regulator of endothelial nitric oxide synthase. Proc Natl Acad Sci USA. 2020; 117:9497-507.

https://doi.org/10.1073/pnas.1918761117 PMID:32300005

15. Wang HH, Lee YN, Su CH, Shu KT, Liu WT, Hsieh CL, Yeh $\mathrm{HI}, \mathrm{Wu}$ YJ. S-Phase Kinase-associated Protein-2 Rejuvenates Senescent Endothelial Progenitor Cells and Induces Angiogenesis in Vivo. Sci Rep. 2020; 10:6646.

https://doi.org/10.1038/s41598-020-63716-y PMID:32313103

16. Ota $\mathrm{H}$, Akishita $\mathrm{M}$, Eto $\mathrm{M}$, lijima K, Kaneki M, Ouchi Y. Sirt1 modulates premature senescence-like phenotype in human endothelial cells. J Mol Cell Cardiol. 2007; 43:571-79.

https://doi.org/10.1016/j.yjmcc.2007.08.008 PMID:17916362

17. Kong L, Wang $\mathrm{Y}$, Wang $\mathrm{H}$, Pan Q, Zuo R, Bai S, Zhang $X$, Lee WY, Kang $Q$, Li G. Conditioned media from endothelial progenitor cells cultured in simulated microgravity promote angiogenesis and bone fracture healing. Stem Cell Res Ther. 2021; 12:47.

https://doi.org/10.1186/s13287-020-02074-y PMID:33419467

18. Xue F, Bai Y, Jiang Y, Liu J, Jian K. Construction and a preliminary study of paracrine effect of bone marrowderived endothelial progenitor cell sheet. Cell Tissue Bank. 2021. [Epub ahead of print]. https://doi.org/10.1007/s10561-021-09932-w PMID:34052984

19. Cañuelo A, Martínez-Romero R, Martínez-Lara E, Sánchez-Alcázar JA, Siles E. The hypoxic preconditioning agent deferoxamine induces poly(ADP-ribose) polymerase-1-dependent inhibition of the mitochondrial respiratory chain. Mol Cell Biochem. 2012; 363:101-08.

https://doi.org/10.1007/s11010-011-1162-1 PMID:22147195

20. Wang $\mathrm{HH}, \mathrm{Wu}$ YJ, Tseng YM, Su CH, Hsieh CL, Yeh HI. Mitochondrial fission protein 1 up-regulation ameliorates senescence-related endothelial dysfunction of human endothelial progenitor cells. Angiogenesis. 2019; 22:569-82. https://doi.org/10.1007/s10456-019-09680-2 PMID:31482366

21. Yoon G, Kim HJ, Yoon YS, Cho H, Lim IK, Lee JH. Iron chelation-induced senescence-like growth arrest in hepatocyte cell lines: association of transforming growth factor beta1 (TGF-beta1)-mediated p27Kip1 
expression. Biochem J. 2002; 366:613-21. https://doi.org/10.1042/BJ20011445 PMID:11945174

22. Chenoufi N, Baffet G, Drénou B, Cariou S, Desille M, Clément $B$, Brissot $P$, Lescoat $G$, Loréal $O$. Deferoxamine arrests in vitro the proliferation of porcine hepatocyte in $\mathrm{G} 1$ phase of the cell cycle. Liver. 1998; 18:60-66.

https://doi.org/10.1111/i.1600-0676.1998.tb00128.x PMID: 9548269

23. Lucas JJ, Szepesi A, Domenico J, Takase K, Tordai A, Terada N, Gelfand EW. Effects of iron-depletion on cell cycle progression in normal human $\mathrm{T}$ lymphocytes: selective inhibition of the appearance of the cyclin Aassociated component of the p33cdk2 kinase. Blood. 1995; 86:2268-80.

PMID:7662974

24. Brodie C, Siriwardana G, Lucas J, Schleicher R, Terada N, Szepesi A, Gelfand E, Seligman P. Neuroblastoma sensitivity to growth inhibition by deferrioxamine: evidence for a block in G1 phase of the cell cycle. Cancer Res. 1993; 53:3968-75.

PMID:8358725

25. Zhao T, Li J, Chen AF. MicroRNA-34a induces endothelial progenitor cell senescence and impedes its angiogenesis via suppressing silent information regulator 1. Am J Physiol Endocrinol Metab. 2010; 299:E110-16.

https://doi.org/10.1152/ajpendo.00192.2010 PMID:20424141

26. Marzabadi MR, Sohal RS, Brunk UT. Effect of ferric iron and desferrioxamine on lipofuscin accumulation in cultured rat heart myocytes. Mech Ageing Dev. 1988; 46:145-57.

https://doi.org/10.1016/0047-6374(88)90122-4 PMID: $\underline{3226156}$

27. Pourcelot E, Lénon M, Mobilia N, Cahn JY, Arnaud J, Fanchon E, Moulis JM, Mossuz P. Iron for proliferation of cell lines and hematopoietic progenitors: Nailing down the intracellular functional iron concentration. Biochim Biophys Acta. 2015; 1853:1596-605.

https://doi.org/10.1016/i.bbamcr.2015.03.009 PMID:25827953

28. Chen C, Liu P, Duan X, Cheng M, Xu LX. Deferoxamineinduced high expression of TfR1 and DMT1 enhanced iron uptake in triple-negative breast cancer cells by activating IL-6/PI3K/AKT pathway. Onco Targets Ther. 2019; 12:4359-77.

https://doi.org/10.2147/OTT.S193507

PMID: $\underline{31213851}$

29. Bajbouj K, Shafarin J, Hamad M. High-Dose Deferoxamine Treatment Disrupts Intracellular Iron Homeostasis, Reduces Growth, and Induces Apoptosis in Metastatic and Nonmetastatic Breast Cancer Cell Lines. Technol Cancer Res Treat. 2018; 17:1533033818764470. https://doi.org/10.1177/1533033818764470 PMID:29562821

30. Harman D. Aging: a theory based on free radical and radiation chemistry. J Gerontol. 1956; 11:298-300. https://doi.org/10.1093/geroni/11.3.298 PMID:13332224

31. Hartley A, Davies M, Rice-Evans C. Desferrioxamine as a lipid chain-breaking antioxidant in sickle erythrocyte membranes. FEBS Lett. 1990; 264:145-48. https://doi.org/10.1016/0014-5793(90)80786-i PMID:2159892

32. Parvar M, Mehrzad J, Chaichi MJ, Hosseinkhani S, Golchoubian H. Quenching effect of deferoxamine on free radical-mediated photon production in luminol and ortho -phenanthroline-dependent chemiluminescence. Chin Chem Lett. 2014; 25:630-34. https://doi.org/10.1016/j.cclet.2014.01.022

33. Pérez VI, Van Remmen H, Bokov A, Epstein CJ, Vijg J, Richardson A. The overexpression of major antioxidant enzymes does not extend the lifespan of mice. Aging Cell. 2009; 8:73-75.

https://doi.org/10.1111/i.1474-9726.2008.00449.x PMID:19077044

34. Mockett RJ, Sohal BH, Sohal RS. Expression of multiple copies of mitochondrially targeted catalase or genomic $\mathrm{Mn}$ superoxide dismutase transgenes does not extend the life span of Drosophila melanogaster. Free Radic Biol Med. 2010; 49:2028-31. https://doi.org/10.1016/i.freeradbiomed.2010.09.029

35. Doonan R, McElwee JJ, Matthijssens F, Walker GA, Houthoofd K, Back P, Matscheski A, Vanfleteren JR, Gems D. Against the oxidative damage theory of aging: superoxide dismutases protect against oxidative stress but have little or no effect on life span in Caenorhabditis elegans. Genes Dev. 2008; 22:3236-41. https://doi.org/10.1101/gad.504808 PMID:19056880

36. Yoon YS, Cho H, Lee JH, Yoon G. Mitochondrial dysfunction via disruption of complex II activity during iron chelation-induced senescence-like growth arrest of Chang cells. Ann N Y Acad Sci. 2004; 1011:123-32.

https://doi.org/10.1007/978-3-662-41088-2 13 PMID:15126290

37. Masuda $H$, Alev C, Akimaru H, Ito R, Shizuno T, Kobori $\mathrm{M}$, Horii $\mathrm{M}$, Ishihara $\mathrm{T}$, Isobe $\mathrm{K}$, Isozaki $\mathrm{M}$, Itoh J, Itoh $\mathrm{Y}$, Okada $\mathrm{Y}$, et al. Methodological development of a clonogenic assay to determine endothelial progenitor cell potential. Circ Res. 2011; 109:20-37. https://doi.org/10.1161/CIRCRESAHA.110.231837 
PMID: 21566217

38. Donneys A, Weiss DM, Deshpande SS, Ahsan S, Tchanque-Fossuo CN, Sarhaddi D, Levi B, Goldstein SA, Buchman SR. Localized deferoxamine injection augments vascularity and improves bony union in pathologic fracture healing after radiotherapy. Bone. 2013; 52:318-25.

https://doi.org/10.1016/j.bone.2012.10.014

PMID:23085084

39. Chekanov VS, Nikolaychik V, Maternowski MA, Mehran R, Leon MB, Adamian M, Moses J, Dangas G, Kipshidze N, Akhtar M. Deferoxamine enhances neovascularization and recovery of ischemic skeletal muscle in an experimental sheep model. Ann Thorac Surg. 2003; 75:184-89. https://doi.org/10.1016/s0003-4975(02)04122-x PMID:12537214

40. Chekanov VS, Zargarian M, Baibekov I, Karakozov P, Tchekanov G, Hare J, Nikolaychik V, Bajwa T, Akhtar M. Deferoxamine-fibrin accelerates angiogenesis in a rabbit model of peripheral ischemia. Vasc Med. 2003; 8:157-62. https://doi.org/10.1191/1358863x03vm491oa

PMID:14989555

41. Holden P, Nair LS. Deferoxamine: An Angiogenic and Antioxidant Molecule for Tissue Regeneration. Tissue Eng Part B Rev. 2019; 25:461-70.

https://doi.org/10.1089/ten.TEB.2019.0111

PMID:31184273

42. Ikeda Y, Tajima S, Yoshida S, Yamano N, Kihira $Y$, Ishizawa K, Aihara K, Tomita S, Tsuchiya K, Tamaki T. Deferoxamine promotes angiogenesis via the activation of vascular endothelial cell function. Atherosclerosis. 2011; 215:339-47.

https://doi.org/10.1016/i.atherosclerosis.2011.01.009 PMID:21315355

43. Li JY, Su CH, Wu YJ, Tien TY, Hsieh CL, Chen $\mathrm{CH}$, Tseng YM, Shi GY, Wu HL, Tsai CH, Lin FY, Yeh HI. Therapeutic angiogenesis of human early endothelial progenitor cells is enhanced by thrombomodulin. Arterioscler Thromb Vasc Biol. 2011; 31:2518-25.

https://doi.org/10.1161/ATVBAHA.111.235143

PMID:21836068 


\section{SUPPLEMENTARY MATERIALS}

\section{Supplementary Figures}
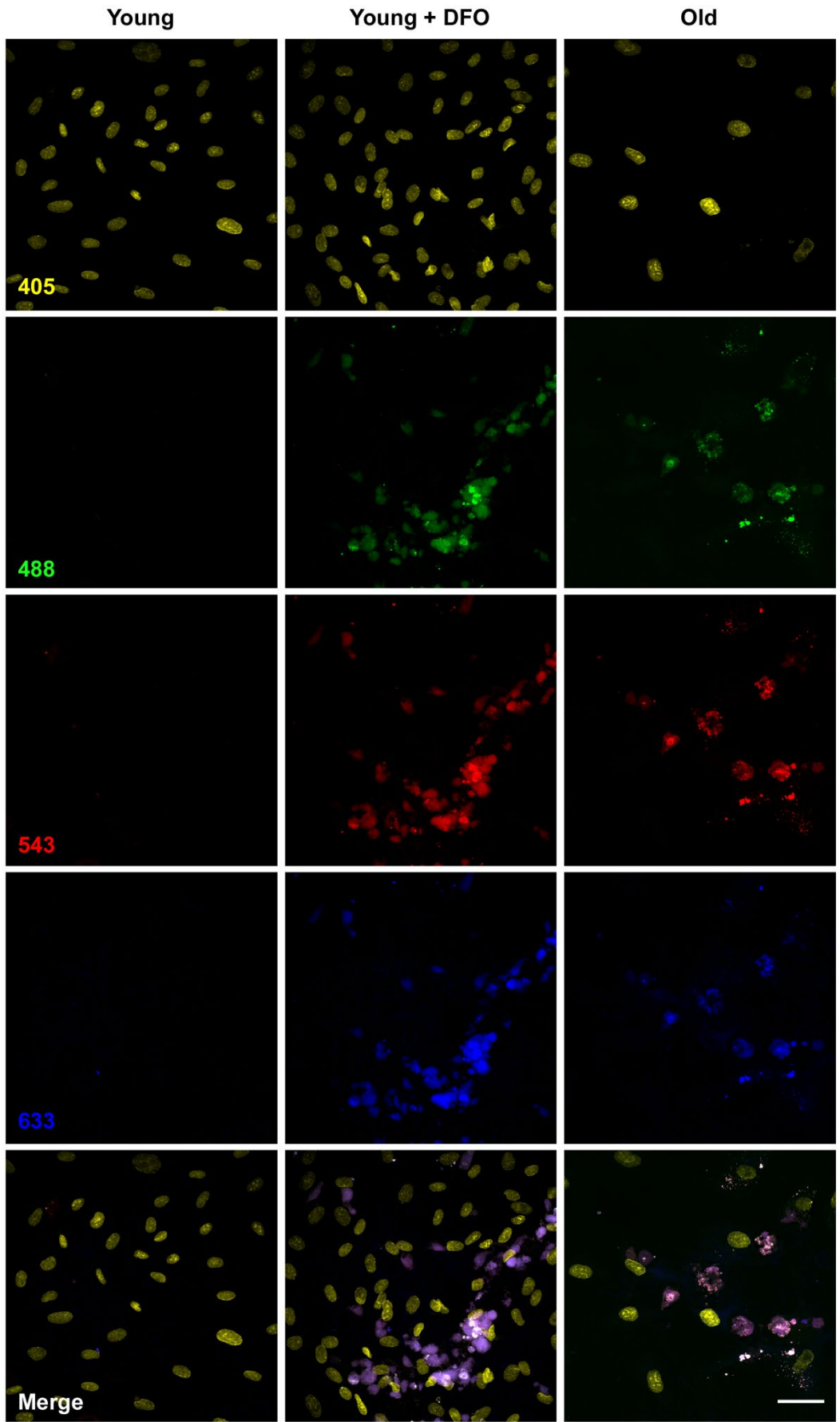

Supplementary Figure 1. DFO accelerates cell senescence with an increase of lipofuscin. Young EPCs (P9) were treated with DFO $(3 \mu \mathrm{M})$ for 4 days. Cells were fixed with ice-cold methanol at $-20^{\circ} \mathrm{C}$ for $5 \mathrm{~min}$. After 3 times of PBS washes, nuclei were stained with DAPI for $10 \mathrm{~min}$. Images were scanned with $405 \mathrm{~nm}$ (UV) to excite DAPI. Of note, signals of lipofuscin autofluorescence were detected in $488 \mathrm{~nm}, 543$ $\mathrm{nm}$ and $633 \mathrm{~nm}$ but not $405 \mathrm{~nm}$ channels. Old EPCs were from same clone of young with additional 9 passages. Images were acquired by Leica SP8 confocal microscope. Scale bar, $50 \mu \mathrm{m}$. 
A

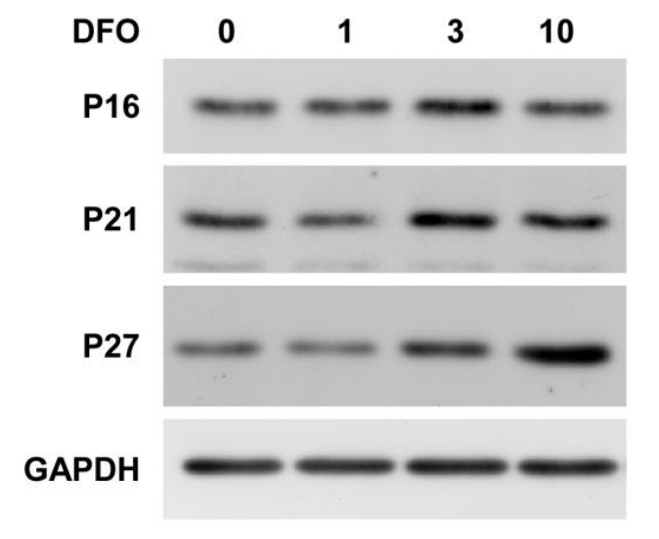

B

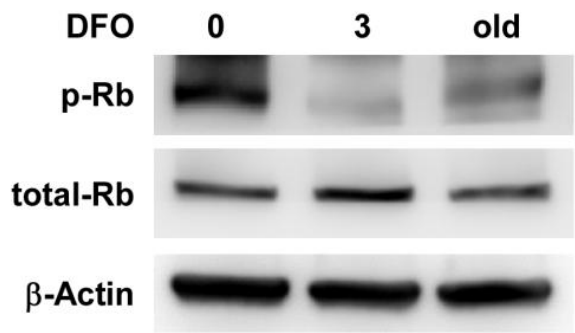

Supplementary Figure 2. Effects of DFO on the expression of senescence-related protein expression. (A) Young EPCs were treated with indicated concentration $(\mu \mathrm{M})$ of DFO for 4 days. (B) Young EPCs were treated with $3 \mu \mathrm{M}$ of DFO for 4 days. Lysates of old EPCs (old) from the same clone of young EPCs with additional 9 passages were loaded for comparison. Whole cell lysates were harvested and resolved by SDS-polyacrylamide gels. Western blots were probed with indicated antibodies. GADPH and $\beta$-Actin are for loading control. Same results were obtained from experiments repeated for three times. 
A
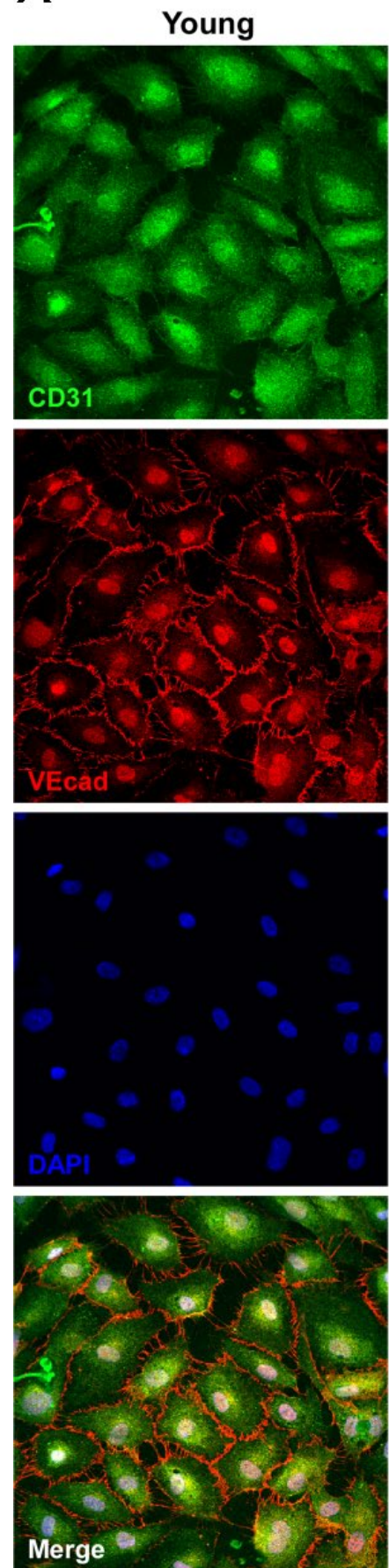

Merge

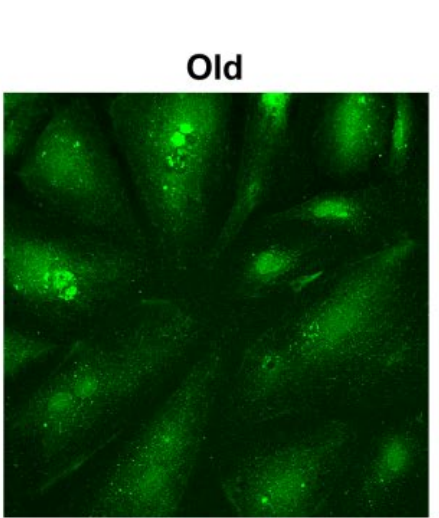

B
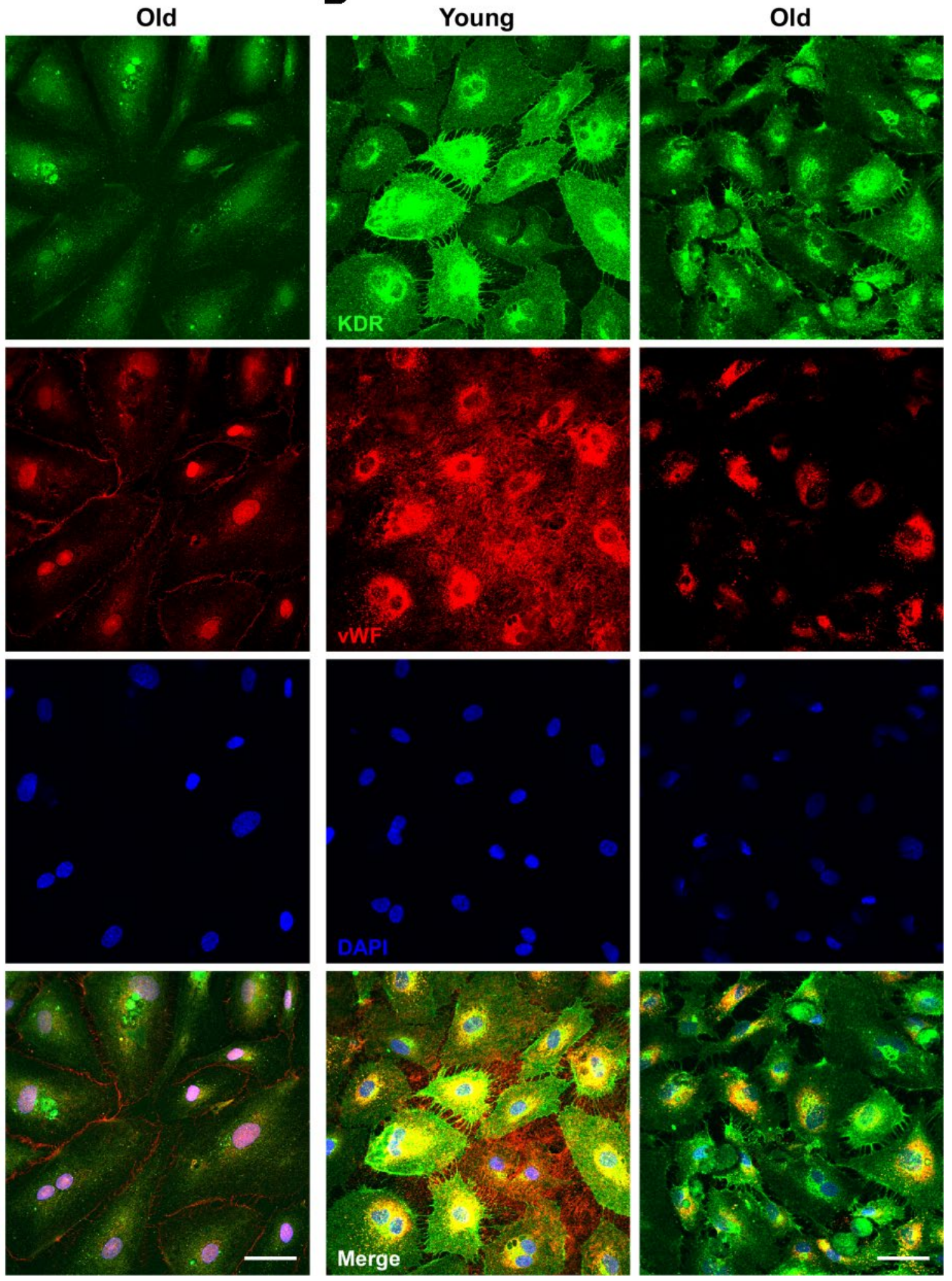

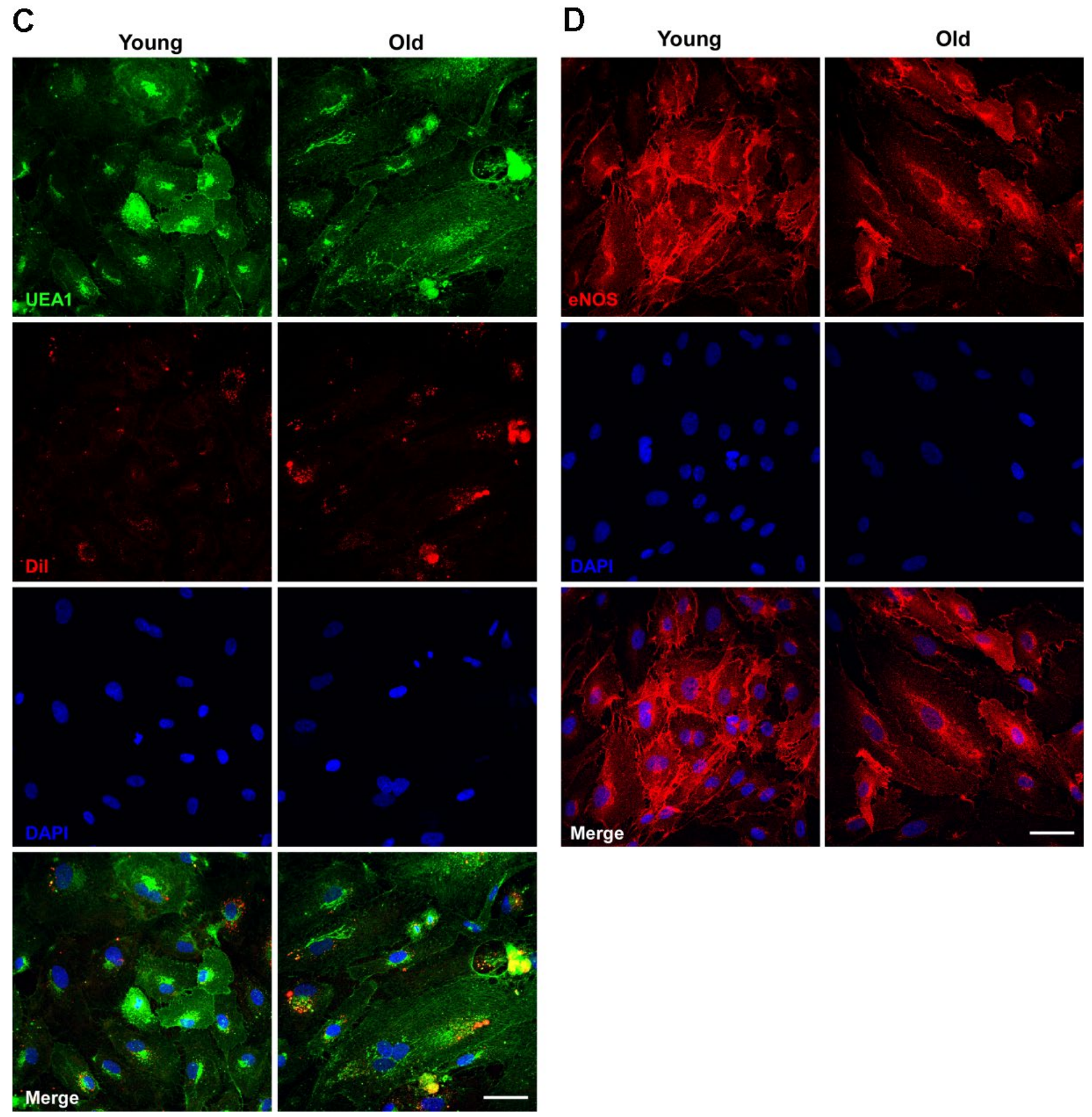

Supplementary Figure 3. Characterization of young and old EPCs. Same clone of young EPCs (P10) with additional 8 passages of old EPCs were harvested and fixed with $4 \%$ paraformaldehyde for 10 min. After 3 times of PBS- $0.2 \%$ Triton X-100 washes and $10 \%$ horse serum blocking for $1 \mathrm{hr}$, cells were stained with indicated antibodies. (A) Cell peripherals were delineated by Ve-cdherin (VEcad) and CD31 is a EPC marker. (B) Cells were stained with KDR for EPCs. VWF is expressed in endothelial cells. (C) Uptake of Dil-acLDL and the staining of UEA1 are hallmarks of EPCs. (D) eNOS is a endothelial marker, correlated to angiogeneic activity. Images were acquired by Leica SP8 confocal microscope. Scale bar, $50 \mu \mathrm{m}$. 